\title{
GEMINATE INALTERABILITY AND LENITION
}

\author{
Robert Kirchner, UCLA
}

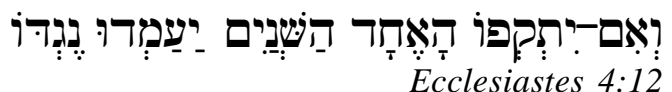

\section{INTRODUCTION}

It is a well-known observation that phonological processes which apply to short segments frequently fail to apply to corresponding long ("geminate") segments. For example, post-vocalic spirantization of velar stops in Tigrinya yields [?a-xalıb] 'dogs' (cf. [k lbi] 'dog'), but [f kk $\mathfrak{f}$ ] 'boasts', not [f $\mathrm{xk} \mathfrak{g}$ ] nor [f $\mathrm{xx} \mathfrak{g}$ ] (Kenstowicz 1982). ${ }^{1}$ This phenomenon of geminate "inalterability" or "blockage" has been the subject of a number of proposals within the framework of Autosegmental Phonology, most influentially Hayes 1986 and Schein \& Steriade $1986 .^{2}$ Subsequent research, however, has revealed that these proposals make seriously incorrect predictions as to the class of processes which display inalterability (see Inkelas \& Cho 1993). As Churma (1988) observes, geminate inalterability holds true as a universally inviolable condition only in the domain of lenition phenomena, a generalization which the classic inalterability approaches fail to capture. Moreover, as Elmedlaoui 1993 notes, within the domain of lenition phenomena, the classic approaches are insufficiently restrictive: they fail to rule out processes which specifically target geminates for lenition, e.g. $/ \mathrm{kk} /->*[\mathrm{xx}]$, or which convert an underlying singleton to a lenited geminate, e.g. /k/ ->*[xx]; and they fail to draw a connection between inalterability and the general markedness of "weaker" (i.e. continuant and voiced (obstruent)) geminates, whether derived via some lenition process or present underlyingly.

In light of major shifts in phonological theory which have occurred since the previous cycle of inalterability research, particularly the development of Optimality Theory (Prince \& Smolensky

\footnotetext{
${ }^{1}$ Here and throughout, transcriptions have been modified to conform with IPA. For consistency, I transcribe geminates with doubling (e.g. kk, aa) rather than the length diacritic (k: a:); this practice is without theoretical significance.

${ }^{2}$ See also Guerssel 1979 for a pre-autosegmental treatment.
} 
1993), it seems timely to reexamine the phenomenon of geminate inalterability, applying the techniques of Optimality Theoretic analysis to a more accurate set of generalizations. Building on the work of Churma and Elmedlaoui, and two recent surveys of lenition typology, Lavoie 1996 and Kirchner (in progress), I identify the following specific generalizations concerning geminates and lenition:

(1) a. No process converts a stop (geminate or otherwise) to a geminate with reduced oral constriction (section 1.2.1).

b. No process converts a (tautomorphemic) geminate stop to a "half-spirantized" cluster, e.g. /kk/ -> *[xk] (section 1.2.2).

c. No process converts a voiceless segment (geminate or otherwise) to a voiced geminate obstruent (section 1.2.3).

d. "Partial geminates" (i.e. homorganic nasal + stop or lateral + stop clusters) behave identically to full geminates with respect to reduction of oral constriction; but, unlike full geminates, they readily undergo voicing (section 1.2.4).

e. No occlusivization nor obstruent devoicing process targets singletons to the exclusion of geminates (section 1.2.5).

f. The presence of a geminate continuant consonant, or voiced geminate obstruent, in the segment inventory of a language (whether derived or underlying) implies the presence of a corresponding non-continuant or voiceless geminate, respectively (section 1.2.6).

"Lenition" may be characterized as temporal or spatial reduction of articulatory gestures; traditionally, this class of processes includes degemination, voicing (in medial position), ${ }^{3}$ spirantization, reduction to sonorants, debuccalization (loss of supralaryngeal constriction), and elision, cf. Lass \& Anderson 1975, Hock 1991. Clearly, an insightful account of these geminate lenition generalizations must be couched within a general theory of lenition. In section 2 , I sketch such a theory, proceeding from the widely shared intuition (cf. Zipf 1949, Donegan \& Stampe 1979, Lindblom 1983, Hock 1991, Kohler 1991, Boesma 1997a, 1997b) that lenition is driven by

\footnotetext{
${ }^{3}$ The phonetic characterization of medial voicing as articulatory reduction is supported in section 3.2.1.
} 
the phonetic imperative to minimize articulatory effort, and relying upon the Optimality Theoretic ("OT") notion of constraint conflict. The generalizations in (1) are shown to follow from this effort-based approach to lenition, coupled with plausible phonetic assumptions concerning the effort required to produce geminates. Specifically:

a. More effort is required to produce a geminate continuant consonant than a geminate stop (the inverse of the situation in singletons), due to the isometric tension required to maintain a steady-state partial constriction for a prolonged interval. Therefore it is never optimal to reduce the oral constriction of a geminate stop (except by shortening it) (section 3.1).

b. More effort is required to produce a voiced geminate obstruent than a voiceless geminate (the inverse of the situation in singleton obstruents in medial position), due to the aerodynamic conditions required to sustain voicing, cf. Ohala 1983. Therefore it is never optimal to voice a geminate obstruent (section 3.2).

In section 4, I propose an account of the (often distinct) behavior of heteromorphemic geminates, relying upon paradigmatic (output-output) faithfulness constraints (e.g. Benua 1995; Flemming 1995). Finally, in section 5, the effort-based approach is compared with alternative approaches, including the classic geminate inalterability proposals.

\section{GENERALIZATIONS}

1.1. THE NON-UNITY OF INALTERABILITY EFFECTS. As a preliminary matter, note that I am not claiming that geminate inalterability effects are to be found only in the domain of lenition processes; nor is it my goal to develop a unified account of all inalterability effects. For example, rounding harmony, i.e. unbounded extension of a lip rounding gesture, is not plausibly regarded as a species of lenition. Yet, in Maltese, rounding harmony fails to apply to long vowels, e.g. /kitbuulik/ -> [kitbuuluk] ('he wrote it to you'), but /Surbitiilim/ -> [ urbutiilim] ('she drank it (fem.) from them'); and virtually the same pattern obtains in Tigre (McCarthy 1979, Schein \& Steriade 1986). Such resistance to rounding neutralization is plausibly analyzed in terms of 
interaction between a constraint which induces rightward spreading of [round] (e.g. Align(rnd,R), cf. McCarthy \& Prince 1993) and a positional faithfulness constraint (Beckman 1997), specifically referring to vowel features in long-vowel position:

(3)

\begin{tabular}{|c|c|c|c|}
\hline & \begin{tabular}{|l} 
IDENT(rnd/long V) \\
\end{tabular} & ALIGN(rnd,R) & IDENT(rnd) \\
\hline 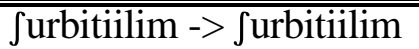 & & ***! & \\
\hline Surbitiilim -> Jurbutiilim & & $* *$ & * \\
\hline 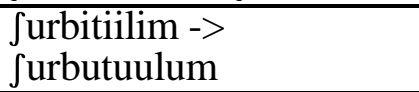 & $* !$ & & $* * *$ \\
\hline kitbuuliik -> kitbuulik & & $* !$ & \\
\hline kitbuuliik -> kitbuuluk & & & $*$ \\
\hline
\end{tabular}

Presumably this positional faithfulness constraint reflects the greater perceptibility of vowel quality distinctions in long vowels, cf. Kaun 1994, Jun 1995, Flemming 1995. For our purposes, the important observation is that the blocking effect under this analaysis is violable: for under the opposite ranking of IDENT(rnd/long V) and ALIGN(rnd,R), no geminate blocking obtains. This prediction is confirmed by Khalkha Mongolian (Street 1962, Schein \& Steriade 1986), in which [round] (and [back]) harmony targets long and short vowels alike: [aabaas] ('father-abl.'), [odoogoos] ('now-abl.'), [gerees] ('house-abl.'), [t[r[[s] ('state-abl.').

In contrast, an examination of the behavior of geminates under lenition reveals crosslinguistically robust generalizations, namely the geminate lenition generalizations in (1), documented below. I take this as motivation for a distinct account of geminate inalterability under lenition: it is the goal of this article to develop such an account. I shall not address the question of whether the remaining non-lenitional geminate inalterability effects can be handled exclusively in terms of the positional faithfulness approach sketched in (3), or whether there may be yet further sources of geminate inalterability effects.

Finally, note that, in assuming that geminate inalterability is not a unified phenomenon, I am not diverging from the consensus of previous approaches. For example, Schein \& Steriade attribute the Maltese and Tigre blocking not to their general principle of geminate blockage, but to a language-specific metrical condition on the harmony rule: [round] can only spread rightward within a foot; and the long vowel serves as the head of a new foot. Churma 1988 appears to concur in 
this non-unified treatment; for he claims that harmony processes never display ("genuine") inalterability effects, despite his awareness of the Maltese and Tigre cases. More explicitly, Inkelas \& Cho (1993: 557) take the position that "the mere survival of a geminate in a language which has a rule that in principle could affect that geminate does not necessarily mean that a genuine case of geminate blocking has occurred." They identify a large class of "pseudo-inalterability" effects, which they attribute to counterfeeding rule ordering, or to the fact that, for various reasons, geminates fail to meet the structural description of the rule in question. ${ }^{4}$

\subsection{DOCUMENTING THE GENERALIZATIONS}

\subsubsection{NO ORALLY REDUCED GEMINATE STOPS. No process converts a stop (geminate} or otherwise) to a geminate with reduced oral constriction. This generalization, together with several of the generalizations below, is a somewhat narrower restatement of Churma's (1988) original claim that "aside from degemination, no weakening process may affect a geminate consonant." 5

1.2.1.1. SPIRANTIZATION. A classic example of such geminate resistance to oral reduction is the Tigrinya spirantization pattern, alluded to in the Introduction, and more fully exemplified below:
a. $\mathrm{k}$ lbi
'dog'
Sarat-ka
'bed-2sg.m.'
g t $1-k i$
'kill-2sg.f. perfect'
b. $\frac{k}{\partial}$ ma-xa
'town-2sg.m.'
mirax-na
'calf-3sg.f.'

\footnotetext{
${ }^{4}$ Only Hayes 1986 appears to assume that all instances of inalterability require a unified treatment. The price Hayes pays for this broad-scope theory is a weakening of its predictive power: for he acknowledges (p. 344) that under his approach it is impossible to identify the necessary conditions for a process to display geminate inalterability.

5 As Elmedlaoui 1993 notes, Churma's claim bears some resemblance the earlier "Inertial Development Principle" of Foley 1977, which states, in essence, that "weak" segments are preferentially targeted by weakening processes, and "strong" segments for strengthening processes. But since Foley explicitly refuses to attribute any consistent phonetic content to his notions of weakening or strengthening, it is difficult to evaluate the empirical predictions which follow from this principle.
} 

Pa-xalıb
'dogs'
?ti xalbi
'the dog'
c. g gt l-a
'kill-3pl.f. perfect'
tl- $-z_{g}$ tl-i
'kill-2sg.f. imperfect'
d. $f \mathrm{k} r$
'boasts'
g t l-na-ka 'we have killed you (masc.)'

That is, post-vocalic velars (4b) and uvulars (c) spirantize, but geminates (d) remain stops. Tiberian Hebrew, with a similar pattern of post-vocalic spirantization of labials, velars, and (nonemphatic) coronals, does indeed display alternations between geminate stops and fricatives (data from Elmedlaoui 1993).

\begin{tabular}{|c|c|c|}
\hline$\underline{\text { Causative Perfect }}$ & $\underline{\text { Basic Perfect }}$ & $\underline{\text { Gloss }}$ \\
\hline zikkeer & zaaxar & remember \\
\hline kippeer & kaa $\phi a r$ & cover \\
\hline biddeel & baaðal & separate \\
\hline pitteeah & paatah & open \\
\hline piggee $\int$ & paaras & meet \\
\hline
\end{tabular}

But, crucially, the spirantized class is limited to surface singletons, thus illustrating a corollary generalization: geminate stops can undergo oral reduction, but only if they surface as singletons. ${ }^{6}$ As Elmedlaoui (1993) observes, the generalization properly focuses not on whether geminates are licit inputs to spirantizaton processes, but whether spirantization processes may yield output geminates. Further examples of geminate blocking of reduction of stops to continuants appear in the following table.

\footnotetext{
6 It might be argued that the target consonant is underlying a singleton, and that the gemination in the 'causative' column is derived, in which case Tiberian Hebrew does not exemplify degemination-cum-spirantization of underlying geminates. In the OT framework, however, since all inputs are admitted by GEN ("Richness of the Base," Prince \& Smolensky 1993, ch. 9), the systematic absence of geminates in the 'basic perfect' column cannot be attributed to the absence of geminate inputs; rather, there must be an active constraint prohibiting geminates in perfect forms, just as there is an active constraint requiring medial geminates in the 'causative' forms. That is, if an input were to contain a geminate stop, it would degeminate and spirantize on the surface.
} 
Table 1: Blocking of spirantization in geminates

\begin{tabular}{|l|l|l|}
\hline \multicolumn{1}{|c|}{ Language } & \multicolumn{1}{|c|}{ Reference } & \multicolumn{1}{c|}{ Description of process } \\
\hline \hline $\begin{array}{l}\text { Florentine } \\
\text { Italian } \\
\text { Hiannelli \& Savoia }\end{array}$ & $\begin{array}{l}\text { Lenition (ranging from spirantization to complete elision, } \\
\text { depending on rate and register) blocked in geminate } \\
\text { obstruents and non-continuants }\end{array}$ \\
\hline Mausa & Hayes 1986 & b,g -> w,r,w in coda, blocked in geminates \\
\hline $\begin{array}{l}\text { (Proto-) } \\
\text { Berber }\end{array}$ & Hayes 1986 & $\begin{array}{l}\text { Stops -> approximants (or apical tap) in the context /[+son,- } \\
\text { nas]_V, blocked in geminates. }\end{array}$ \\
\hline Tamil & Keating et al. 1983 & $\begin{array}{l}\text { Stops -> fricatives (context-free), blocked in geminates7 } \\
\text { gemingates }\end{array}$ \\
\hline $\begin{array}{l}\text { Tiberian } \\
\text { Hebrew }\end{array}$ & $\begin{array}{l}\text { Ha y e s } \\
\text { Elmedlaoui 1993 } 1986,\end{array}$ & $\begin{array}{l}\text { Post-vocalic non-emphatic stops spirantize, blocked in } \\
\text { geminates }\end{array}$ \\
\hline Tigrinya & $\begin{array}{l}\text { Hayes 1986, Schein \& } \\
\text { Steriade 1986 }\end{array}$ & $\begin{array}{l}\text { Post-vocalic velars and uvulars spirantize, blocked in } \\
\text { geminates }\end{array}$ \\
\hline $\begin{array}{l}\text { Tümpisa } \\
\text { Shoshone }\end{array}$ & Dayley 1989 & $\begin{array}{l}\text { Spirantization, flapping blocked after a homorganic nasal } \\
\text { and in geminates; voicing blocked in geminates }\end{array}$ \\
\hline
\end{tabular}

Note that inalterability under spirantization holds true for geminate nasal as well as oral stops, as seen (non-vacuously) in Tümpisa Shoshone:

\footnotetext{
${ }^{7}$ At some point prior to Modern Berber, this spirantization pattern came to be reanalyzed as a process occlusivizing geminate fricatives, see Saib 1974.
} 


\begin{tabular}{|c|c|c|c|c|}
\hline a. & $\operatorname{simm}_{30}$ tI & $->$ & sirw’ II & 'ten' \\
\hline & senu & $->$ & seju & 'therefore' \\
\hline b. & tapett $\int \mathrm{i}$ & $->$ & taßett $\int i$ & 'sun' \\
\hline & tsitoohi & $->$ & tsiðoohi & 'push' \\
\hline & puhakantı & $->$ & puhayandi & 'shaman' \\
\hline c. & uttunna & $->$ & uttunna & 'to give' \\
\hline & kimmakinna & $->$ & kimmayinna & 'to come here' \\
\hline d. & patıasippI & $->$ & parıasıppı & 'ice' \\
\hline & uttunna & $->$ & uttunna & 'to give' \\
\hline & punikka & $->$ & punikka & 'see, look at' \\
\hline e. & taziumbi & $->$ & taziumbi & 'star' \\
\hline & Intamı?i & $->$ & Indaw` Iri & 'your little brother' \\
\hline & tıppisipunki & $->$ & tıppifiфungi & 'stinkbug' \\
\hline
\end{tabular}

Non-initial singleton nasals spirantize (6a), as do oral stops (b); but this lenition is blocked in geminate nasal (c) and oral stops (d), as well as partial geminate clusters (e). ${ }^{8}$

1.2.1.2. Flapping. Tümpisa Shoshone (and Hausa) further demonstrate that the geminate inalterability effect is not limited to spirantization per se: geminate inalterability also obtains under flapping (i.e. reduction of closure duration in coronal stops, see Banner-Inouye 1995). Nor is this so merely by definition (i.e. the closure duration of stop cannot be radically temporally reduced, as in a flap, and still remain a geminate): for it is logically possible, though unattested, that a flapping process applying to a geminate stop would yield a long trill. Moreover, the same effect shows up in partial geminates in Lamani (Trail 1970): flapping is blocked after a homorganic nasal or lateral.

1.2.1.3. GEnERALIZATION. In contrast to this wealth of cases showing geminate inalterability under processes of spirantization, flapping, and reduction to approximants, cases

\footnotetext{
8/t/ lenites by flapping rather than spirantizing when it follows a back vowel. According to Dayley, in this same environment, $/ \mathrm{n} /$ does not lenite; it is plausible, however, that it reduces to a nasalized flap, paralleling the behavior of /t/: the distinction between [n] and [r] is a subtle one, which Dayley might understandably have overlooked.
} 
where these processes apply to geminates (without concomitant degemination) appear to be completely unattested, based on the previous inalterability literature, and the lenition surveys of Lavoie 1996 and Kirchner (in progress). (Indeed, far from reducing their oral constriction, there is a positive tendency for geminate consonants to occlusivize, see section 1.6.)

To my knowledge, the only ostensible (partial) counter-example to geminate inalterability under spirantization involves a detail of the Florentine Italian facts (Giannelli \& Savoia 1979). Singleton intervocalic stops lenite, from fricatives all the way to $\varnothing$, depending on speech rate and register, particularly in intervocalic position:

\begin{tabular}{|c|c|c|c|c|c|}
\hline & $\begin{array}{l}\text { Slow/ } \\
\text { Careful }\end{array}$ & $\begin{array}{l}\text { Moderatel } \\
\text { Natural }\end{array}$ & $\begin{array}{l}\text { Fast/ } \\
\text { Careless }\end{array}$ & $\begin{array}{l}\text { Extremely } \\
\text { Fast/Careless }\end{array}$ & \\
\hline /la tavola/ & la tavola & la \avola & la (ð્)aola & la aola & 'the table' \\
\hline le $\mathrm{d}$ rme/ & e $\mathrm{d}$ rme & e $\precsim$ rme & e ð $\mathrm{rme}$ & $\mathrm{e}_{\mathrm{J} \mathrm{I}} \mathrm{me}_{\perp}$ & 's/he sleeps' \\
\hline
\end{tabular}

This spirantization (and further reduction) is generally blocked in geminate stops; however, at the fastest rate and lowest register of speech, in intervocalic position, even geminates can spirantize, to very close fricatives. ${ }^{9}$

$\begin{array}{llllll} & \begin{array}{l}\text { Slow/ } \\ \text { Careful }\end{array} & \begin{array}{l}\text { Moderatel } \\ \text { Natural }\end{array} & \begin{array}{l}\text { Fast/ } \\ \text { Careless }\end{array} & \begin{array}{l}\text { Extremely } \\ \text { Fast/Careless }\end{array} & \\ \text { /brutto/ } & \text { brutto } & \text { brutto } & \text { brutto } & \text { bruțo } & \text { 'ugly' } \\ \text { /freddo/ } & \text { freddo } & \text { freddo } & \text { freddo } & \text { freðָðָo } & \text { 'cold' }\end{array}$

However, it is not clear, despite the transcription, that these spirantized segments are in fact phonetically geminates. Giannelli \& Savoia give no data on the actual duration of these consonants; but as this is essentially a very-fast-speech phenomenon, it is unlikely that the duration of the fast-speech "geminate" approaches the typical duration of a geminate in slow or normal speech. ${ }^{10}$ Assuming that the lenited geminates have in fact degeminated, in this phonetic sense,

\footnotetext{
${ }^{9}$ Such a counterexample might be dismissed as mere "phonetics," beyond the purview of phonological theory. However, since my approach recognizes no modular distinction between phonological and phonetic processes, I cannot avail myself of this traditional "out."

${ }^{10}$ Giannelli \& Savoia could reasonably transcribe these spirantized segments as "geminates," notwithstanding their phonetic degemination, i.e. a substantial reduction in their duration, because they do not neutralize with the category of short consonants. In Florentine the consonant "length" contrast is supported by at least three cues in addition to
} 
they do not constitute a counterexample to the generalization. On the contrary, these facts provide a striking example of geminate resistance to lenition. In this dialect, in which all singleton stops reduce to weak approximants or $\emptyset$, even in normal speech, geminates do not spirantize at all, except in the fastest speech style, when they (arguably) are no longer realized with typical geminate duration.

\subsubsection{LENITION OF GEMINATES OTHER THAN REDUCTION OF ORAL CONSTRICTION IN}

STOPS. Finally, note that the generalization distinguishes between reduction of oral constriction in geminate stops and other forms of lenition. It has already been noted that geminates can lenite by degeminating, and that degemination potentiates further lenition in Tiberian Hebrew (5) and Florentine (8). Hebrew also contains a case of degemination tout court: "guttural" (pharyngealized) consonants degeminate, context-free (Hayes 1986). Although such degemination does constitute (temporal) reduction, the output ceases to be a geminate, and thus the No ORALLY REDUCED GEMINATE STOPS generalization is maintained.

Geminates also commonly undergo loss of a distinct release of the first half of a geminate,

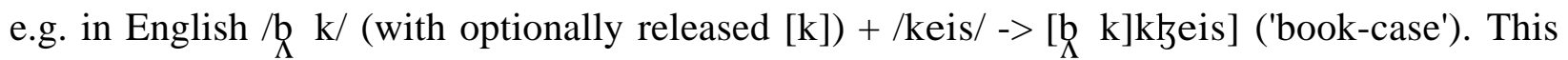
elimination of the opening gesture is clearly a species of articulatory reduction, although this occurs so ubiquitously in geminates that its status as a lenition process is easily overlooked. This loss of release presumably lies behind Ancient Greek "deaspiration" of the first half of a geminate stop (Hayes 1986). For aspiration (in the typical sense of post-aspiration, i.e. long lag voice onset time) is a property of the stop's release; thus an unreleased stop cannot bear (post-)aspiration.

The distinction between oral reduction of stops and other forms of lenition also appears in Florentine rhotic reduction (Giannelli \& Savoia 1979). Florentine, like many Romance dialects, has a contrast between a long alveolar trill (e.g. [korriðojo] 'corridor') and a short trill or tap (e.g. [la $\left.\int \mathrm{e}\{\mathrm{r} / \mathrm{r}\} \mathrm{a}\right]$ 'the wax'). In natural speech styles, both the long trill (e.g. [korriðojo] 'corridor')

consonant duration itself: (a) the shortened duration of the vowel that precedes the geminate (Smith 1992); (b) in the case of the voiceless geminate, an aspirated release, as Gianelli \& Savoia note; and (c) a more fortis constriction compared to singletons in the same context (i.e. the lenited geminates are near-stops whereas the lenited singletons are weak approximants or $\varnothing)$. 
and the short trill or tap (e.g. [la $\int \mathrm{e}\{\mathrm{r} / \mathrm{r}\}$ a] 'the wax') optionally lenite to approximants, without any temporal reduction of the the longer rhotic: [ko iðojo] vs. [ $\left.\int_{\mathcal{I}} \mathrm{a}\right] .^{11}$

1.2.2. NO HALF-SPIRANTIZATION. No process converts a (tautomorphemic) geminate non-continuant to a "half-spirantized" cluster, e.g. /kk/->*[xk]. We have already seen in the previous section that spirantization processes are no more able to yield half-spirantized clusters than they are able to yield fully spirantized geminates. Thus, in Tigrinya, [f $x k \mathfrak{g} f$ ] and [f $x \underset{\partial}{f}$ ] are both equally impossible outputs for /f $\mathrm{kk} f /$. More generally, cases of spirantization of the first half of a (tautomorphemic) geminate appear to be unattested, based on the previous inalterability literature and the lenition surveys. In heteromorphemic geminates, however, halfspirantization is attested, to wit, in Tigrinya: /mırak-ka/ -> [miraxka] ('calf-2sg.m.'). On the other hand, this distinct behavior of heteromorphemic geminates under spirantization in Tigrinya is not universal: in Tiberian Hebrew, heteromorphemic geminates resist spirantization just as the tautomorphemic geminates do: e.g. [kaarattii] ('I cut'), cf. [kaarat] ('he cut').

Furthermore, it is necessary to distinguish between half-spirantization (in the narrow sense of reduction to a fricative), and half-gliding of geminates, which is attested in Maxakalí (Gudschinsky, Popovich and Popovich 1970; Hayes 1986): /mattık/ -> [mºg tıx] ('happy'),

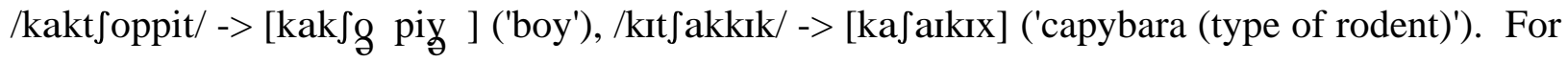
our purposes, the crucial observation is that the Maxakalí vocoid corresponding to the first half of the geminate is not a steady-state constriction, but a (somewhat attenuated) transition from the vowel into the following (singleton) obstruent. ${ }^{12}$ It is also necessary to distinguish halfspirantization from half-debuccalization, attested in the Icelandic process of "pre-aspiration," Thráinsson 1979, Hayes 1986, whereby voiceless geminate stops reduce to h + stop clusters (e.g. /kappi/ -> [kahpi] ('hero'). This is simply degemination of the oral constriction gesture, leaving the long glottal abduction gesture unchanged (cf. Clements 1985).

\footnotetext{
${ }^{11}$ This reduction is not restricted to extremely fast speech; moreover, the two lenited rhotics appear to be distinguished solely by duration; thus it does not seem plausible to claim here, as I did with regard to spirantization, that the lenited geminate is in fact phonetically degeminated.

${ }^{12}$ Gudschinsky et al., p. 77, explicitly describe these vocoids as "phonetic transition phenomena."
} 
(9)

\begin{tabular}{|c}
\multicolumn{1}{c}{$\mathrm{p} \mathrm{p}$} \\
\hline oral closure \\
\hline glottal abduction \\
\hline
\end{tabular}$\rightarrow$ oral closure

Since the oral constriction degeminates, this process (vacuously) conforms to the NO HALFSPIRANTIZATION generalization, as well as the NO ORALLY REDUCED GEMINATE STOPS generalization.

1.4. NO VOICING OF GEMINATES. No process converts a voiceless segment (geminate or otherwise) to a voiced geminate obstruent. Blocking of voicing in geminate obstruents has already been exemplified in the Tümpisa Shoshone data (6). That is, all obstruents undergo voicing, except in utterance-initial position, and in (full) geminates (Dayley 1989). ${ }^{13}$ Additional examples of geminate inalterability under voicing include:

Table 2: Blocking of voicing in geminates

\begin{tabular}{|l|l|l|}
\hline \multicolumn{1}{|c|}{ Language } & \multicolumn{1}{|c|}{ Reference } & \multicolumn{1}{c|}{ Description of process } \\
\hline \hline Berber & Inkelas \& Cho 1993 & $\begin{array}{l}\text { Pharyngealized obstruents -> voiced (context-free), blocked } \\
\text { in geminates }\end{array}$ \\
\hline Cuna & Keating et al. 1983 & Voicing in medial position, blocked in geminates \\
\hline $\begin{array}{l}\text { Florentine } \\
\text { Italian } \\
\text { Giannelli \& Savoia }\end{array}$ & $\begin{array}{l}\text { In fast/casual speech styles, voiceless stops, which } \\
\text { otherwise spirantize to voiceless fricatives or approximants, } \\
\text { further reduce to voiced approximants; this is blocked in } \\
\text { geminates. }\end{array}$ \\
\hline $\begin{array}{l}\text { Gallo- } \\
\text { Romance }\end{array}$ & $\begin{array}{l}\text { Jacobs \& Wetzels } \\
\text { Me88 }\end{array}$ & $\begin{array}{l}\text { Sound change: intervocalic/t/ underwent voicing, while /tt/ } \\
\text { degeminated without voicing }\end{array}$ \\
\hline Malayalam & Mohanan 1986 & $\begin{array}{l}\text { Stops become voiced in the context /+son_V or /+nas__; } \\
\text { blocked in geminates }\end{array}$ \\
\hline Somali & Armstrong 1964 & Intervocalic voicing, blocked in geminates \\
\hline Tamil & Keating et al. 1983 & $\begin{array}{l}\text { Voicing (and spirantization) in medial position, blocked in } \\
\text { geminates }\end{array}$ \\
\hline $\begin{array}{l}\text { Tümpisa } \\
\text { Shoshone }\end{array}$ & Dayley 1989 & Non-initial obstruents are voiced, blocked in geminates \\
\hline
\end{tabular}

In contrast, voicing processes which do apply to full geminates appear to be unattested, based on the previous inalterability, and the lenition surveys. See also Hock 1991, who concurs that such processes are unattested, but views this as an accidental gap. Indeed, far from undergoing voicing processes, geminate stops show a positive tendency to devoice, as discussed in section 1.6 below.

${ }^{13}$ In addition, utterance-final syllables devoice in their entirety, e.g. [...tippi $\left.\int i \phi u \eta k i\right]_{\text {Utterance }}$ ('stinkbug'). 
An interesting question is whether there is a "no half-voicing" generalization, paralleling the NO HALF-SPIRANTIZATION generalization above. The inalterability literature and the lenition surveys do not report any cases of half-voicing. But the principal perceptual correlate of the "voiced/voiceless' opposition in obstruents is voice onset time, a property of the release. Since the first portion of a geminate rarely if ever has its own release, it could well be the case that the first portion has a substantial amount of closure voicing (e.g. [b]p] or [bp]p]), yet the geminate as a whole sounds voiceless, and is so transcribed in the descriptive grammars, because its release, after the second half of the geminate, is voiceless. Thus, more careful phonetic studies of ostensible cases of geminate blocking of voicing are required before this generalization can be verified.

1.5. NO REDUCTION OF PARTIAL GEMINATES. "Partial geminates" (i.e. homorganic nasal + stop or lateral + stop clusters) behave identically to full geminates with respect to reduction of oral constriction; but, unlike full geminates, they readily undergo voicing. Blocking of spirantization in partial geminates has already been discussed in connection with Tümpisa Shoshone (6e). This inalterability effect is further exemplified in Spanish (Harris 1969): 

a. aßa 'bean'
kalßo 'bald'
aða 'fairy'
aya 'make'
$--$
aßla 'speak'
aðlateres 'lackies'
alyo 'something'
arßol 'tree'
arðe 'burn'
aßra 'will have'
paðre 'father'
aylomerar 'to cluster'
xajßo (no gloss)
najðen 'nobody'
aryamasa 'mortar'
aßjerto 'open'
aðjestrar 'to guide'
ayrio 'sour'
ewßolja (no gloss)
dewða 'debt'
kajya 'fall'
aßwelo 'grandfather'
aðwana 'customhouse'
siyjendo 'following'
aðßerso 'unfavorable'
aßðomen 'abdomen'
sewrma 'zeugma'
sußmarino 'submarine'
aðmirasjon 'admiration'
aywero 'fortune-teller'
sußylotal 'subglottal'
diaynostiko 'diagnostic'
b. bomba 'bomb'
donde 'where'
ganga 'bargain'
kaldo 'hot'

That is, non-initial voiced stops spirantize (10a), except when following a homorganic nasal or lateral (b). Additional cases appear in the following table:

Table 3: Blocking of spirantization, flapping in partial geminates

\begin{tabular}{|l|l|l|}
\hline Language & \multicolumn{1}{|c|}{ Reference } & \multicolumn{1}{c|}{ Description of process } \\
\hline \hline Lamani & Trail 1970 & Flapping blocked after a homorganic nasal or lateral \\
\hline Malayalam & Mohanan 1986 & $\begin{array}{l}\text { Spirantization, flapping do not apply following a } \\
\text { homorganic nasal }\end{array}$ \\
\hline $\begin{array}{l}\text { Proto- } \\
\text { Bantu }\end{array}$ & Greenberg 1948 & $\begin{array}{l}\text { Spirantization (context-free), blocked after homorganic } \\
\text { nasal }\end{array}$ \\
\hline $\begin{array}{l}\text { Tümpisa } \\
\text { Shoshone }\end{array}$ & Dayley 1989 & Spirantization blocked in homorganic nasal-stop clusters \\
\hline
\end{tabular}

More generally, oral reduction of all or part of a tautomorphemic homorganic nasal stop or lateralstop cluster is unattested in the inalterability literature and the lenition surveys. Far from spirantizing, consonants show a positive tendency to occlusivize when adjacent to a homorganic nasal, as in the following Kikuyu post-nasal alternations (Padgett 1992): 
(11)

\begin{tabular}{|c|c|c|}
\hline mbureete & 'lop off' & cf. $\beta$ ura \\
\hline mbaareet $\varepsilon$ & 'look at' & cf. $\beta$ aara \\
\hline ndeheet $\varepsilon$ & 'pay' & cf. reha \\
\hline nduyeete & 'cook' & cf. ruya \\
\hline jgoreett $\varepsilon$ & 'buy' & cf. yora \\
\hline ggaeet $\varepsilon$ & 'divide' & cf. yaja \\
\hline
\end{tabular}

Similarly, pre-nasal occlusivization is seen in certain dialects of American English, e.g. [bidn s] ('business'), idnit ('isn't it').

However, nasal + stop clusters show no parallel blocking of voicing. This is seen in Tümpisa Shoshone (6), where voicing applies to post-nasal stops (though spirantization is blocked), e.g. /Intamıi/ -> [Indaw`ıii] ('your little brother'). A virtually identical pattern of postnasal voicing, but blocking of spirantization, is observed in Malayalam (Mohanan 1986). Indeed, Hayes \& Stivers (in progress) observe that stops very commonly undergo voicing in post-nasal position (regardless of homorganicity), as seen in the following alternations (12b) from Wembawemba:
a. Itaka/ tak 'to hit'
/milpa/ milg 'to twist'
b. /jantin/ jandin 'me'
/panpar/ panb $\mathrm{r} \quad$ 'shovel'

See also Pater 1996, Itô and Mester 1986.

1.2.5. NO EXCLUSIVE OCCLUSIVIZATION OR DEVOICING OF SINGLETONS. No occlusivization or obstruent devoicing process targets singletons to the exclusion of geminates. This claim, the flip side of geminate resistance to oral reduction and voicing, is originally due to Churma (1988), who refers to these processes more loosely as "strengthening." Thus, one may find languages in which both geminate and singleton obstruents are uniformly realized as stops (that is, all obstruents occlusivize), e.g. Warray, Mayali, and numerous other Australian languages (see Evans 1996); and there are languages in which only geminates 
occlusivize, e.g. Modern Berber (Schein \& Steriade 1986), Luganda (/jj, ww/ -> [33, gg], Clements 1986, Churma 1988), and Malayalam (/rr/ -> [tt], Mohanan 1986). But there appears to be no language in which singletons occlusivize to the exclusion of geminates. Similarly, there are languages in which both geminate and singleton obstruents uniformly surface as voiceless (that is, all obstruents devoice), e.g. Delaware (Maddieson 1984); and Ohala 1983 cites Nubian as a case of geminate devoicing:

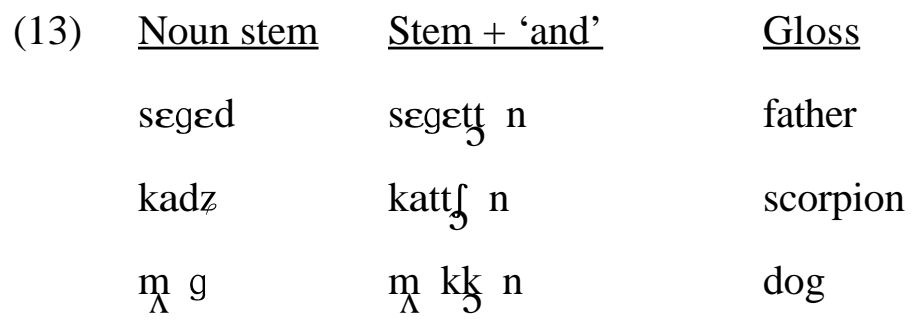

(See also the devoicing of the geminate rhotic in Malayalam, noted above). But there appears to be no language in which singletons devoice to the exclusion of geminates.

1.2.6. INVENTORY ASYMMETRIES. The presence of a geminate continuant consonant, or voiced geminate obstruent, in the segment inventory of a language (whether derived or underlying) implies the presence of a corresponding non-continuant or voiceless geminate, respectively. This generalization is a narrower restatement of Elmedlaoui's original claim that segment inventories never have "weaker" (i.e. higher sonority) geminates without also having "stronger" geminates. ${ }^{14}$ We have already seen that geminates resist spirantization and (obstruent) voicing processes. However, this is not exclusively a claim about lenition processes; for the same asymmetry is seen in segment inventories, regardless of the phonemic status of the "weaker" geminate. This generalization is borne out by the inventories discussed in Maddieson 1984.

First consider the stop/fricative asymmetry:

Table 4: Segment inventories: geminate stops and fricatives

\begin{tabular}{l|l|l|}
\hline labial & coronal & dorsal
\end{tabular}

\footnotetext{
${ }^{14}$ To the extent that Elmedlaoui generalizes this claim in terms of the sonority hierarchy, it is false. Elmedlaoui's claim predicts, for example, that all languages with long vowels also have geminate consonants (falsified by a significant share of the world's languages, including Yidip, Dixon 1977); and that all languages with geminate sonorant consonants also have geminate obstruents (falsified by Ponapean, which has geminate nasals and liquids, but no geminate obstruents, Rehg \& Sohl 1981).
} 


\begin{tabular}{|l|l|l|l|}
\hline geminate & Punjabi & Punjabi & Punjabi \\
stop/affricate & Finnish & Finnish & Finnish \\
& Yakut & Yakut & Yakut \\
& Japanese Maranungku & Japanese Maranungku & Japanese Maranungku \\
& Delaware & Delaware & Delaware \\
& Lak & Lak & Aak \\
& Wolof & Arabic & Arabic \\
& Arabic & Shilha & Shilha \\
& Shilha & Somali & Nomali \\
& Somali & Kaliai & \\
& & Wichita & Lak \\
& Arabic & Punjabi & Arabic \\
& Shilha & Finnish & Shilha \\
& Greenlandic & Yakut & Greenlandic \\
& & Japanese & \\
& & Lak & \\
& & Arabic & \\
& & Shilha & \\
& & Wichita & Greenlandic \\
& & Iraqw & \\
\hline
\end{tabular}

The only reported cases of inventories with a geminate fricative but no corresponding stop are Greenlandic and Iraqw. It is clear, however, from Rischel's (1974) description (Maddieson's principal source) that Greenlandic does have surface geminate stops as well as fricatives :

$\begin{array}{ll}\text { suraajuwippuq } & \text { 'is incessant' } \\ \text { kamittaq } & \text { 'new boot' } \\ \text { puwijuwikkijuppaa } & \text { 'never forgets it' } \\ \text { qaqqaq } & \text { 'mountain' }\end{array}$

(Apparently, the claim that Greenlandic has no geminate stops is based on an analysis under which these geminates are derived from underlying clusters.) As for Iraqw, Maddieson characterizes the inventory as having a distinction between [s] and [ss], with no length distinction in the stops. I have not been able to obtain Whiteley's (1958) description, on which Maddieson's Iraqw inventory is based; however, Nordbustad's (1985) grammar of Iraqw makes clear that geminate stops are present in the inventory: 
gwa tuntukka' 'she has not covered it'

Curiously, Nordbustad gives no examples with [ss]. Other descriptions of the Iraqw sound system available to me (Maghway 1995, Mous 1992) do not mention any length contrasts at all. Nordbustad observes that "double consonants are rare." Apparently, Iraqw presents a case of a rather marginal (perhaps diachronically waning) consonant length contrast, in stops as well as fricatives; hence the variation in the descriptions.

Finally, consider the voicing asymmetry:

Table 5: Segment inventories: geminate voiced and voiceless obstruents

\begin{tabular}{|l|l|l|l|}
\hline & labial & coronal & dorsal \\
\hline geminate & Punjabi & Iraqw & Punjabi \\
voiceless & Finnish & Punjabi & Finnish \\
& Yakut & Finnish & Yakut \\
& Japanese & Yakut & Japanese \\
& Maranungku & Japanese & Maranungku \\
& Delaware & Maranungku & Delaware \\
& Lak & Delaware & Lak \\
& Arabic & Lak & Arabic \\
& Shilha & Arabic & Shilha \\
& Greenlandic & Shilha & Greenlandic \\
& & Wichita & \\
& & Lak & \\
\hline geminate & Punjabi & Japanese & Somali \\
voiced & Wolof & Punjabi & Lunjabi \\
obstruent & Arabic & Yakut & Arabic \\
& Shilha & Arabic & Shilha \\
& Somali & Shilha & Somali \\
& & & Greenlandic \\
\hline
\end{tabular}

The only reported cases of inventories with voiced geminate obstruents but no voiceless counterparts are Somali and Wolof. However, Armstrong 1964 (Maddieson's source for the Somali inventory) states that the Somali "voiced" geminates in question "do not sound fully voiced," and in some cases are in fact completely voiceless. ${ }^{15}$ As for Wolof, Sauvageot's (1965)

\footnotetext{
${ }^{15}$ An exception is the post-alveolar stop, transcribed as [d]/[dd] which Armstrong describes as fully voiced, in both the singleton and the geminate. Armstrong notes, however, that this sound is not a simple voiced stop. Unlike the rest of the stop series, it involves pharyngeal constriction (like Semitic emphatics), as well as being somewhat
} 
grammar of the Dyolof (or Jolof) dialect (Maddieson's source for the Wolof inventory) in fact lists a number of forms with surface voiceless geminates: ${ }^{16}$

$\begin{array}{ll}\text { tappu } & \text { 'needle' } \\ \text { atte } & \text { 'to judge' } \\ \text { fettzi } & \text { 'undress, untie' } \\ \text { tekki } & \text { (no gloss) }\end{array}$

Moreover, more recent grammars and dictionaries of (standard) Wolof (e.g. Ka 1994, Munro \& Gaye 1991) make clear that voiceless geminates are part of the inventory; and Omar Ka (p.c.) states that he is unaware of any dialect variation within Wolof with respect to the presence of voiceless geminates.

In sum, the segment inventories listed by Maddieson 1984 contain, upon closer examination, no actual counterexamples to the INVENTORY ASYMMETRIES generalization.

\section{LENITION IN PHONETICALLy-BASED OPTIMALITY THEORY}

2.1. SUMMARY OF PREVIOUS APPROACHES. The modern theoretical literature has had relatively little to say about lenition processes, despite their pervasiveness in sound systems. Donegan \& Stampe (1979) made a number of proposals concerning the ordering of lenition and fortition rules, and speculated on the phonetic basis of lenition in considerations of ease of articulation; but they did not offer a restrictive formal characterization of lenition processes. Previous formal treatments of lenition have generally been limited to analyses of voicing and spirantization processes in particular languages as autosegmental feature-spreading (e.g. Kenstowicz 1982, (James) Harris 1984; Mascaró 1983, 1987; Cho 1990; Lombardi 1991), without attempting a unified treatment of these and other lenition processes, such as degemination and elision. Similarly, Jacobs’ (1994) Optimality Theoretic account of Gallo-Romance voicing and

implosive. Moreover, there is no voiceless correspondent to [d] in the singleton series, as there are for the other voiced singleton stops.

16 Maddieson's characterization appears to be based on Sauvageot's statement (p. 17) that "Le parler possède une corrélation de gémination consonantique. Celle-ci ... est, semble-t-il, limitée aux occlusives sonores; ... aux nasales; ... [et] à la latérale." Unfortunately, Sauvageot does not explain how this characterization is to be reconciled with the voiceless geminate forms cited above, which appear in later sections of the grammar. 
spirantization simply stipulates a set of formally unrelated constraints prohibiting continuant and voiced segments in "lenition environments," without attempting any general characterization of such environments. A notable exception to the prevailing "ad hoc-ery" is (John) Harris' (1990) treatment of lenition as deletion of phonological structure, within the framework of Government Phonology. However, Harris does not address geminate inalterability; nor is it clear under his approach how the inalterability effect would be obtained, except by stipulation.

Finally, an idea often suggested in the literature (but rarely fleshed out in explicit analyses of actual sound patterns) is that lenition consists of promotion of segments on the sonority scale (or equivalently, demotion on a "strength" scale, taken to be the inverse of sonority) e.g. Foley 1977, Churma 1988, Clements 1990, Hock 1991, Ní Chiosáin 1991, Elmedlaoui 1993, Lavoie 1996):

a. $\quad$ Sonority scale (Dell \& Elmedlaoui 1985) stops < voiceless fricatives $<$ voiced fricatives $<$ nasals $<$ liquids $<$ high vowels/glides < low vowels

b. Strength scale (composite, from Hock 1991 and Lavoie 1996) geminate stops $>$ voiceless stops $>$ voiced stops $>$ voiceless fricatives $>$ voiced fricatives $>$ liquids $>$ laryngeals $>$ glides $>\varnothing$

In view of its apparent popularity, I must make clear why this sonority-promotion approach seems to me fundamentally unpromising. First, this approach predicts such unattested processes as lenition of fricatives to nasal stops. It likewise predicts lenition from high to low vowels; whereas, on the contrary, vowel reduction frequently involves raising (as well as centralization or elision). ${ }^{17}$ Moreover, the match between the "sonority" and "strength" scales is far from perfect: geminate stops, at the strong end, do not behave as less sonorous than singleton stops for syllabification purposes (indeed, they do not pattern as single segments at all, but as clusters); and at the weak end, it is impossible to speak of $\varnothing$ (i.e. a deleted segment) as having any sonority at all, let alone being maximally sonorous. Further note that no unified phonetic correlate of "strength" has

\footnotetext{
${ }^{17}$ E.g., the Bedouin Hijazi Arabic chain shift $\mathrm{a} \rightarrow \mathrm{i} \rightarrow \varnothing$ in short, medial, unstressed vowels (Al-Mozainy 1979).
} 
previously been identified (see Bauer 1988). ${ }^{18}$ But if the strength scale is not reducible to sonority, or to any other independently motivated property, then it amounts to a mere list of stipulations: class X may lenite to class Y, Y may lenite to Z, etc.

2.2. AN EFFORT-BASED APPROACH. The core proposal of this article is that lenition patterns are expressed in terms of Optimality Theoretic conflicts between a scalar effort minimization constraint, LAZY, on the one hand (which generally favors reduction of articulatory gestures, ideally to $\varnothing$ ), and on the other hand a set of lenition-blocking constraints, for which we may take as emblematic the family of "faithfulness" constraints (favoring preservation of underlying specifications). Thus, spirantization, for example, is analyzed in terms of rankings where LAZY dominates faithfulness to continuancy (18a); under the opposite ranking (b), spirantization is blocked:

a.

\begin{tabular}{|l||c|c|}
\hline$/ \mathrm{b} /$ & LAZY & IDENT(cont) \\
\hline \hline $\mathrm{b}$ & $* * !$ & \\
\hline$\beta$ & $*$ & $*$ \\
\hline
\end{tabular}

\begin{tabular}{l|l|c|c|}
\cline { 2 - 4 } b. & /b/ & IDENT(cont) & LAZY \\
\cline { 2 - 4 } & $\mathrm{b}$ & & $* *$ \\
\hline$\beta$ & $* !$ & $*$ \\
\hline
\end{tabular}

This approach is part of an emerging research program which weds the substance of functional phonetic explanation with the formalism of OT constraint interaction: this goal appears, to varying degrees, in such recent works as Steriade 1993, 1995, 1996; Kaun 1994; Flemming 1995, 1997; Jun 1995; Silverman 1995; Myers 1996; Beckman 1997; Boersma 1997a, Boersma 1997b, Boersma 1997c, Boersma 1997d; Hayes 1997; MacEachern 1997; Gordon (in progress); and Kirchner (in progress). More generally, the approach continues a line of research on phonetic explanation in phonology, associated with phoneticians such as Ohala (1981, 1983), Lindblom (1983, 1990), Browman \& Goldstein (1990, 1992); and Kohler (1991). The principal assumptions and results of this approach to lenition are highlighted below.

\footnotetext{
${ }^{18}$ The notion of phonological "sonority" suffers from the same lack of phonetic grounding, Kawasaki 1982, Ohala 1992; see also Clements 1990 (defending sonority as a phonological construct, despite its failure to correspond to any unified phonetic dimension).
} 


\subsubsection{EFFORT}

2.2.1.1 WHAT IS EFFORT? I assume that the notion of effort to which LAZY refers is the sum ofneuromuscular activation levels required to achieve some set of articulatory gestures, or more precisely, a mental estimate of this activation. Information on the extent of muscle activation is available to the nervous system via sensors known as "muscle spindles," which, together with joint receptors, form the proprioceptive feedback system (Borden \& Harris 1994: 147-148). Thus it seems plausible that speakers are capable of extrapolating from past experience of articulatory feedback, to compute an estimate of the activation levels required for a given gesture. Formally, I assume that effort cost is computed for each candidate representation, as part of the candidate generating function, GEN. ${ }^{19}$

However, in light of the difficulty of measuring such global neuromuscular activation directly, ${ }^{20}$ phoneticians have typically approached articulatory effort from a biomechanical rather than a neuromuscular perspective. Specifically, following Nelson 1980, I treat effort as an analog of biomechanical force (i.e. mass · velocity). And following Lindblom 1983, I model the relation

\footnotetext{
${ }^{19}$ It may be objected that effort is a predictable, gradient phonetic property, whereas phonological representations may contain only potentially constrastive properties (see, e.g., Keating 1984, Lombardi 1991). This objection is addressed at length in Kirchner (1997). To summarize the response: in an OT framework which includes featurespecific faithfulness constraints, it is possible to distinguish between contrastive and non-contrastive properties in terms of constraint ranking, without excluding any phonetic properties from the phonological representation. Roughly speaking, a feature $\mathrm{F}$ behaves as contrastive if the corresponding faithfulness constraint crucially dominates some constraint $\mathrm{C}(\mathrm{F})$ on the surface distribution of $\mathrm{F}$, so that both underlying values of $\mathrm{F}$ surface unchanged in the relevant context; under the opposite ranking, $\mathrm{C}(\mathrm{F})$ determines the surface value of $\mathrm{F}$, regardless of its underlying value, and so $\mathrm{F}$ is predictable. Moreover, if the universal constraint set contains no faithfulness constraint referring to $\mathrm{F}$, then $\mathrm{F}$ behaves as non-contrastive under any constraint ranking, since no constraint then militates against neutralization of underlying distinctions in F. I assume that no faithfulness constraint refers to effort levels; thus, it follows that information regarding effort levels may be included within phonological representations, without thereby predicting spurious sound systems in which distinctions in effort levels (e.g. [ \pm effort>500]) function as contrastive features.

${ }^{20}$ Activation levels of a specific group of muscle fibers can be measured using electromyography, cf. Stone 1996; however, there are currently no experimental techniques for measuring global neuromuscular activation: and without such a comprehensive picture, one is in the position of guessing the shape of the proverbial elephant from the shape its tail. Note that proprioceptive feedback of muscle activity is not straightforwardly accessible to conscious introspection (Borden \& Harris, p. 148). Moreover, naive intuitions of "difficulty" are probably unreliable here; for such intuitions may merely reflect the speaker's familiarity with a sound or sound sequence. A phonological account based on such intuitions would thus be circular: some sound does not occur (in a particular language, or universally) because it is difficult/unfamiliar; and it is difficult/unfamiliar because it does not occur.
} 
between force and articulator movement (specifically, for consonantal constriction) using a computational simulation of a simplified mass-spring system, schematized in (19):21
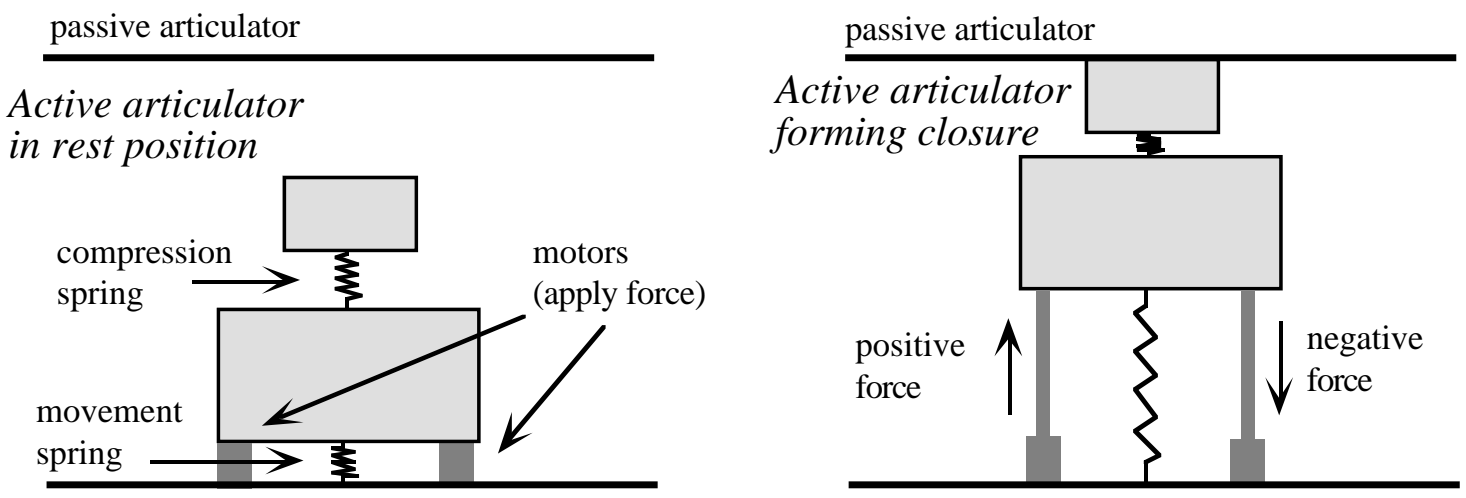

The equations implemented by this model are:

$$
\begin{aligned}
& a_{n e t}(t)=\frac{U_{\text {pos }}(t)+U_{n e g}(t)}{m}-\left(g+b_{m} v(t)+k_{m} s(t)\right) \\
& \text { If } s(t)>h \text { then } \\
& a_{n e t}(t)=\frac{U_{p o s}(t)+U_{n e g}(t)}{m}-\left(g+b_{m} v(t)+k_{m} s(t)+b_{c} v(t)+k_{c} s(t-h)\right) \\
& v(t)=v(t-1)+a_{n e t}(t-1) \\
& s(t)=s(t-1)+v(t-1) \\
& E=\sum_{t=1}^{t=n}\left(\left|U_{p o s}(t)\right|+\left|U_{n e g}(t)\right|\right)
\end{aligned}
$$

where the above symbols have the following meanings and values:

\footnotetext{
${ }^{21}$ This model is not presented as a conclusive answer to these issues, but as a first step towards an answer. Plainly, the modeling of articulatory effort is an extremely complex problem, involving numerous parameters whose values are not yet well established.
} 
(21)

\begin{tabular}{|l|l|l|}
\hline \multicolumn{1}{|c|}{ Symbol Meaning } & $\begin{array}{c}\text { Value assigned } \\
\text { (if constant) }\end{array}$ \\
\hline \hline$a_{\text {net }}$ & Net acceleration & \\
\hline$U_{\text {pos }}$ & Positive force & \\
\hline$U_{\text {neg }}$ & Negative force (a non-positive number) & \\
\hline$v$ & Velocity & \\
\hline$s$ & Displacement & \\
\hline$t$ & Time & \\
\hline$E$ & Effort & 1 \\
\hline$n$ & number of timeslices in gesture & .001 \\
\hline$m$ & Articulator mass & .1 \\
\hline$g$ & Gravity & .008 \\
\hline$b_{m}$ & Damping of articulator movement spring & \\
\hline$k_{m}$ & Stiffness of articulator movement spring & \\
\hline$b_{c}$ & $\begin{array}{l}\text { Damping of articulator compression } \\
\text { spring }\end{array}$ & .2 \\
\hline$k_{c}$ & $\begin{array}{l}\text { Stiffness of articulator compression } \\
\text { spring }\end{array}$ & .016 \\
\hline$h$ & $\begin{array}{l}\text { Height of passive articulator, relative to } \\
\text { active articulator's rest position }\end{array}$ & $20 \mathrm{~mm}$ \\
\hline
\end{tabular}

In this model, the user specifies temporal and spatial targets for articulator movement, as follows:

\begin{tabular}{|c|c|c|c|c|c|}
\hline & $\begin{array}{l}\text { Upper bound } \\
\text { of spatial } \\
\text { target (in } \\
\text { mm) }\end{array}$ & $\begin{array}{l}\text { Lower bound } \\
\text { of spatial } \\
\text { target (in } \\
\text { mm) }\end{array}$ & $\begin{array}{l}\text { Consonant } \\
\text { start (in } \\
\text { msec) }\end{array}$ & $\begin{array}{l}\text { Consonant } \\
\text { end (in } \\
\text { msec) }\end{array}$ & \begin{tabular}{|l} 
Articulator \\
must \\
return to 0 \\
by: \\
(in msec) \\
\end{tabular} \\
\hline $\begin{array}{l}\text { Singleton } \\
\text { fricative }\end{array}$ & \begin{tabular}{|l|}
19.33 \\
\end{tabular} & 18 & 120 & $125^{22}$ & 245 \\
\hline $\begin{array}{l}\text { Singleton } \\
\text { stop }\end{array}$ & $\mathrm{n} / \mathrm{a}$ & 20 & 120 & 180 & 300 \\
\hline $\begin{array}{l}\text { Geminate } \\
\text { fricative }\end{array}$ & 19.33 & 18 & 120 & 240 & 360 \\
\hline $\begin{array}{l}\text { Geminate } \\
\text { stop }\end{array}$ & $\mathrm{n} / \mathrm{a}$ & 20 & 120 & 240 & 360 \\
\hline $\begin{array}{l}\text { Half-spirantized } \\
\text { geminate: } \\
\text { fricative portion } \\
\text { (transition interval) } \\
\text { stop portion } \\
\end{array}$ & $\begin{array}{l}19.33 \\
\text { n/a } \\
\text { n/a } \\
\end{array}$ & $\begin{array}{l}18 \\
\mathrm{n} / \mathrm{a} \\
20\end{array}$ & $\begin{array}{l}120 \\
175 \\
185 \\
\end{array}$ & $\begin{array}{l}175 \\
185 \\
240 \\
\end{array}$ & \begin{tabular}{|l}
$\mathrm{n} / \mathrm{a}$ \\
$\mathrm{n} / \mathrm{a}$ \\
360 \\
\end{tabular} \\
\hline
\end{tabular}

${ }^{22}$ It may be objected that singleton fricatives are not typically much shorter than stops, as these targets suggest. However, the goal is to model continuants which are the output of spirantization processes. These low-precision gestures have, at most, brief, non-strident friction, a generalization documented in Kirchner (in progress), and analyzed along similar lines to the present treatment of geminate fricatives. 
The model finds, by gradient-ascent learning, the function of force against time which achieves these targets with the least possible effort. The output of the model consists of graphs of displacement vs. time and force vs. time, and a value for total effort. In addition, the force function itself is subject to a constraint: the targets are achieved using at most one positive and one negative (bell-shaped) force "impulse," whose timing, magnitude, and breadth are determined by the learning algorithm. This restriction reflects the conjecture that the neuromuscular system is not capable of independently manipulating the precise force applied to an articulator at each instant in time (23a). Instead, we assume a more global control regime, which imposes a smooth contour on the force function $(23 b)$ :

"Impulse" restriction on mass-spring model:

a. Prohibits force functions like this:

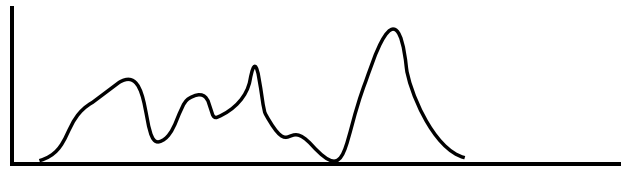

b. Requires force functions like this:

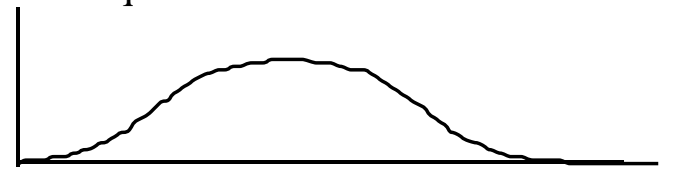

The learning algorithm perturbs the magnitude, time, and breadth of the positive and negative force impulses, and then checks to see if the result reduced the error. If so, the new values are adopted; if not, the old ones are retained. Error is defined first as failure to meet the temporal and spatial criteria as defined above; once error in this sense falls below some threshold (set to 1.0 in the current version), error reduction takes the form of minimization of total effort.

Under this model, the general assumption that reduction of oral constriction in a singleton stop (e.g. by spirantization) constitutes a reduction of effort, implicit in the effort-based treatment of spirantization above, is substantiated: 
(24)

a.

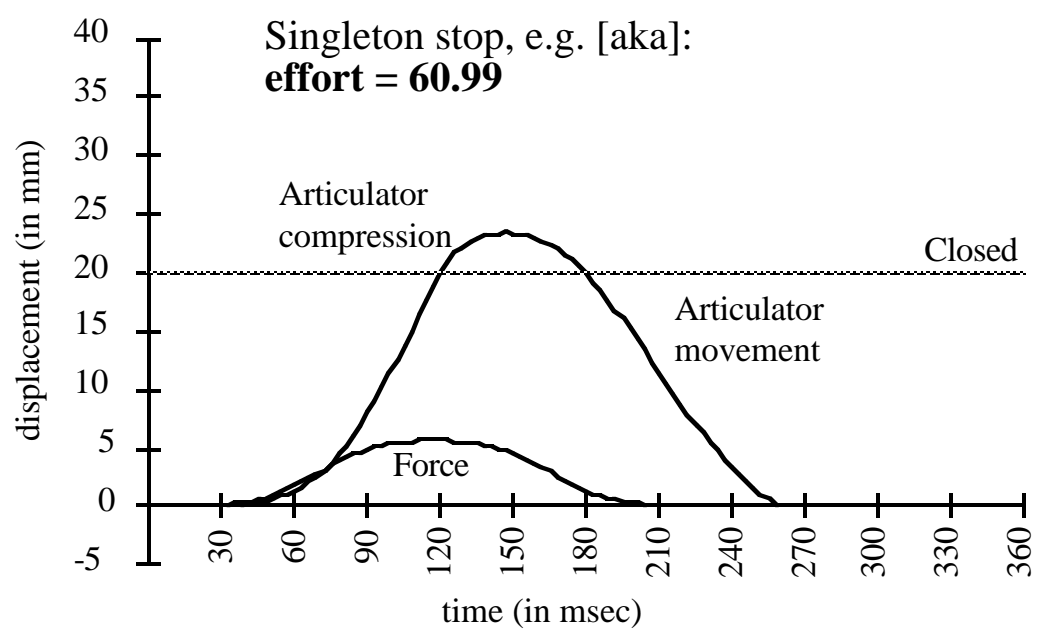

b.

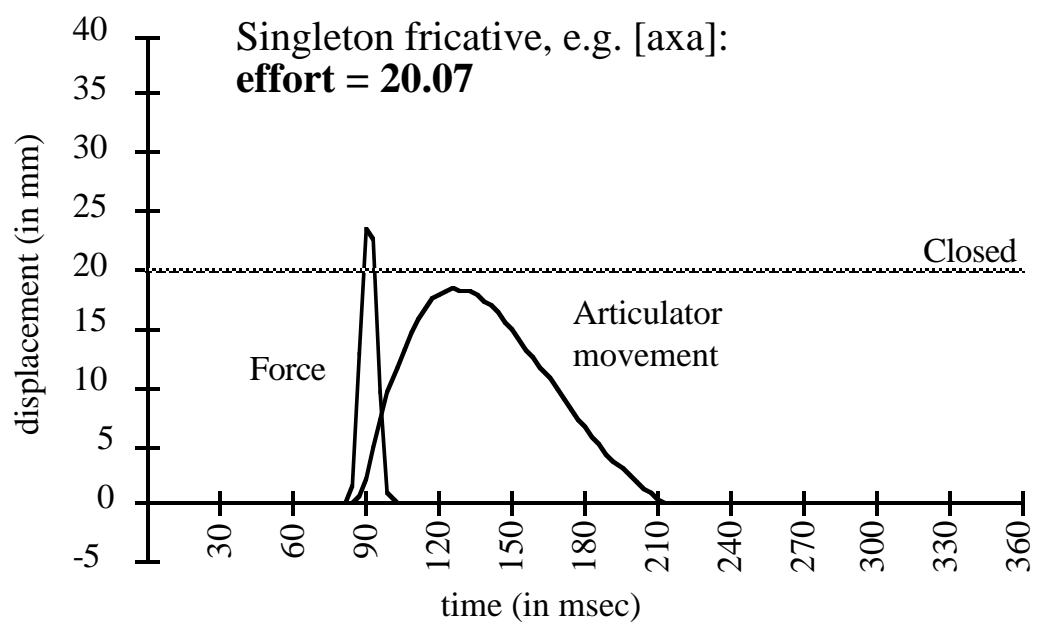

2.2.1.3. VoICING. The connection between effort reduction and voicing lenition is not as immediately apparent. Westbury \& Keating 1986, however, demonstrate that, due to aerodynamic conditions, in utterance-medial position when preceded by a voiced sonorant, obstruents of normal duration (typically 50-80 msec) undergo passive voicing, unless they are devoiced by active abduction (or constriction) of the glottis. ${ }^{23}$ Voicing lenition (as in Somali) can therefore be understood as the elimination of a glottal abduction gesture.

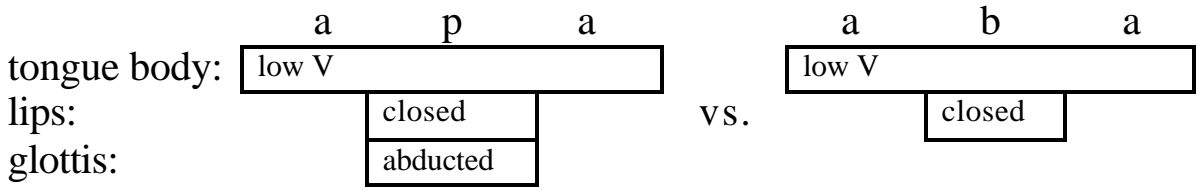

\footnotetext{
${ }^{23}$ Westbury \& Keating, like Chomsky \& Halle 1968, assume that the glottis is adducted in speech-ready rest position.
} 
Voicing in this context thus affords an effort savings, because the devoicing (glottal abduction) gesture necessarily involves more effort than no gesture at all. Moreover, in many (though not all) languages the closure gesture in voiceless stops is of greater magnitude than in voiced stops, partially vindicating the traditional notion that voiceless stops are "fortis," i.e. involving greater muscular force, and voiced stops "lenis" (see generally Ladefoged \& Maddieson 1996, chapter 3 ). For languages in which this is the case, the greater effort cost of the more fortis gesture would provide additional impetus for voicing lenition. Thus there appears to be a sound phonetic basis for the traditional classification of medial voicing processes as a species of lenition.

2.2.2. Lenition-Blocking Constraints. Following McCarthy and Prince 1995, I posit a segmental faithfulness constraint MAX (all input segments have correspondents in the output, i.e. don't delete), and a set of featural faithfulness constraints of the form IDENT(F) (corresponding segments in the input and output have the same value for F, i.e. don't change the value of F). ${ }^{24}$ Thus, spirantization, for example, is analyzed in terms of rankings where LAZY dominates IDENT(cont):

\begin{tabular}{|c|c|c|c|c|}
\hline$/ \mathrm{b} /$ & MAX & IDENT(son) & LAZY & IDENT(cont) \\
\hline $\bar{b}$ & & & $* * * !$ & \\
\hline $\bar{\beta}$ & & & $* *$ & $*$ \\
\hline $\mathrm{w}, \beta$ & & $* !$ & $*$ & \\
\hline$\varnothing$ & $* !$ & & & \\
\hline
\end{tabular}

Further lenition, to an approximant or $\emptyset$, is blocked by other faithfulness constraints, namely MAX and IDENT(son). More generally, the structural changes occurring in a given language (with respect to lenition) depend upon which of the faithfulness constraints are ranked below LAZY: if IDENT(voi), then voicing; if IDENT(sonorant), then reduction to a sonorant (e.g. a glide or flap); if IDENT(place features), then debuccalization; if MAX, then elision; if no faithfulness constraint, then no lenition at all. Thus, lenition receives a unified characterization, in terms of the ranking schema LAZY » faithfulness.

\footnotetext{
${ }^{24} \mathrm{McC}$ arthy and Prince's anti-epenthesis constraint, DEP, is also assumed, though it will play no role in the present analyses.
} 
Restriction of lenition to particular contexts can be obtained through context-sensitive IDENT constraints, an enrichment motivated in Jun 1995, Steriade 1995, 1996, and Beckman 1997, and grounded in the phonetic observation that many distinctions are perceptually more salient, or more crucial to lexical access, in particular contexts, such as word-initial, onset, and stressed position. Intuitively speaking, there is greater impetus to lenite in contexts where there is relatively little perceptual "bang" for the articulatory "buck." Thus, coda lenition (e.g. Hausa, see Table 1) can be captured as follows: IDENT(cont/onset) outranks the more general IDENT(cont) constraint; and LAZY falls between these:

\begin{tabular}{|l||c|c|cc|}
\hline & $\begin{array}{c}\text { IDENT(cont } \\
\text { /onset) }\end{array}$ & LAZY & IDENT(cont) & IDENT(son) \\
\hline \hline abda -> ab.da & & $* * !$ & & $*$ \\
\hline abda -> aw.da & & $*$ & $*$ & $*$ \\
\hline \hline aba -> a.ba & & $* *$ & & $*$ \\
\hline aba -> a.wa & $* !$ & $*$ & $*$ & $*$ \\
\hline
\end{tabular}

Blocking of lenition in other perceptually prominent positions, e.g. word-initial and stressed positions, can similarly be attributed to context-sensitive faithfulness constraints: IDENT(F/\#__),

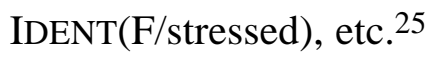

Note, however, that for cases of complementary distribution, e.g. no word-initial fricatives, and no non-initial stops, the use of faithfulness constraints as lenition-blockers is insufficient.

\footnotetext{
${ }^{25}$ Restriction of lenition to particular places of articulation may similarly be obtained in terms of place-specific faithfulness constraints, e.g. \{IDENT(cont/lab), IDENT(cont/cor) $\} »$ LAZY » IDENT(cont/dors) results in spirantization of dorsal consonants exclusively. Alternatively, such patterns may be obtained by allowing place-specific LAZY constraints: the ranking $\left\{\mathrm{LAZY}_{\mathrm{cor}}, \mathrm{LAZY}_{\text {lab }}\right\} » \operatorname{IDENT}(\mathrm{cont}) » \mathrm{LAZY}_{\text {dors }}$ yields the same pattern. Both approaches seem equally ad hoc, as is the typology: there do not appear to be any valid cross-linguistic generalizations (e.g. "if coronals lenite, then so do labials") concerning place of articulation and lenition (cf. Kirchner, in progress; pace Foley 1977). In any case, the choice between place-specific faithfulness and place-specific LAZY approaches is extraneous to our present concerns, therefore I will not pursue it.
} 


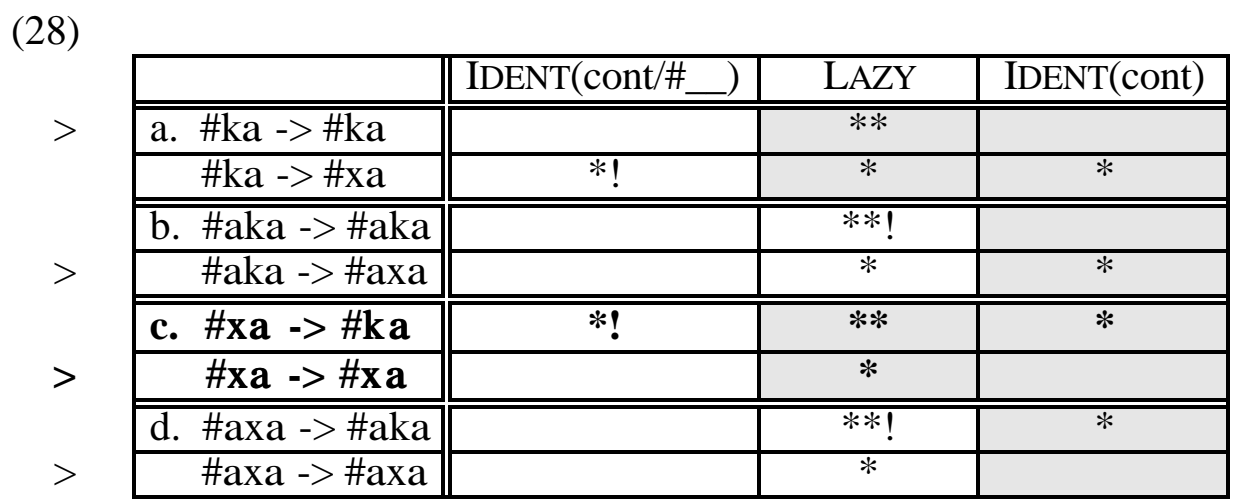

If, as in (28c), some word-initial obstruent is underlyingly [+cont] (and the OT tenet of Richness of the Base (Prince \& Smolensky 1993, ch. 9) prevents us from excluding such an input), both faithfulness and LAZY favor the fricative candidate; thus it is impossible to rule out word-initial fricatives. An additional class of lenition-blocking constraints is required: these must not only block lenition, but actively induce fortition, e.g. requiring word-initial obstruents to be realized as stops (*[+cont,-son]/\#_). It seems plausible that these fortition constraints are, like the contextsensitive faithfulness constraints, grounded in perceptual considerations. For example, the release burst of a stop contains salient place of articulation cues (e.g. Wright 1996); thus, by militating in favor of consonants with a release burst, this constraint can be viewed as enhancing the perceptibility of the consonant; and the allocation of more robust cues to word-initial position may be viewed as reflecting the greater importance of word-initial consonants in lexical access (see Flemming 1995 for a more general treatment of perceptual enhancement in phonology). However, precise formulation of the fortition constraints is largely extraneous to our present concerns. In the interest of expository simplicity, for purposes of this article, I will focus on the faithfulness constraints, treating them as emblematic of the larger class of lenition-blocking constraints.

2.2.3. Intervocalic Position. Context-sensitive lenition-blocking constraints, however, do not afford an insightful treatment of one of the typologically most common lenition contexts, intervocalic position (as in Florentine Italian). This context, however, may be attributed 
to the greater displacement (hence effort) required to achieve a given degree of consonantal constriction when flanked by more open segments (cf. Grammont 1939, Beckman et al. 1992). ${ }^{26}$
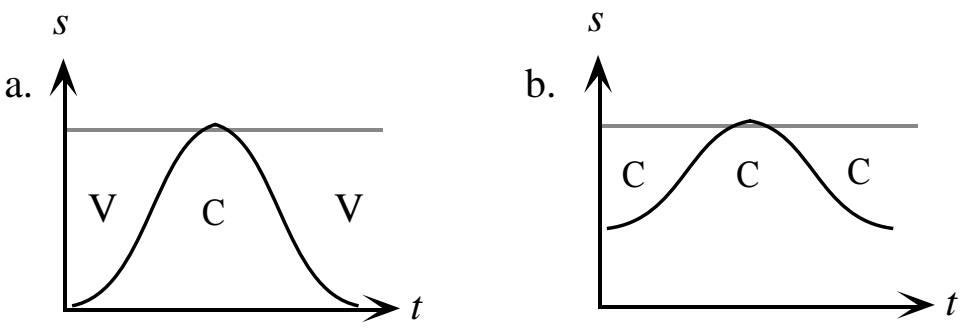

To formally capture this idea, the scalar LAZY constraint is decomposed into a series of binary

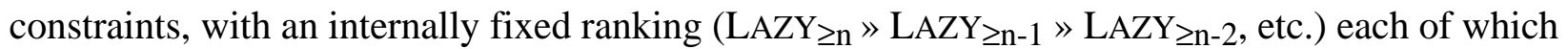
prohibits effort at or above a particular threshold.

\begin{tabular}{|c|c|c|c|}
\hline & $\mathrm{LAZY}_{\geq \mathrm{x}+1}$ & PRES(cont) & $\mathrm{LAZY}_{\geq \mathrm{x}}$ \\
\hline 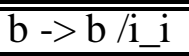 & $* !$ & & $\bar{*}$ \\
\hline b-> $\beta / i \_i$ & & * & * \\
\hline$\overline{\mathrm{b}->\mathrm{b} / \mathrm{r} \_\mathrm{i}}$ & & & $\bar{*}$ \\
\hline $\mathrm{b}->\beta / \mathrm{r}_{-} \mathrm{i}$ & & $* !$ & \\
\hline
\end{tabular}

If $x+1$ denotes the minimum level of effort required to achieve closure in a [b] in intervocalic context, a pattern of spirantization of $/ \mathrm{b} /$ in intervocalic position, but not in, e.g., post-rhotic position, obtains under the ranking of effort thresholds shown in (30). Post-vocalic lenition contexts (e.g. Tigrinya, Tiberian Hebrew) can be understood as the union of the coda context (see section 2.2.2) and the intervocalic context.

2.2.4. RATE- AND REGISTER-SENSITIVE LENITION. Ceteris paribus, the faster the speech rate, the greater the velocity (hence effort) required to achieve a given degree of consonantal constriction. Rate-conditioned lenition thus can likewise be captured in terms of a ranking of effort thresholds.

\footnotetext{
${ }^{26}$ The effect of the flanking vowels on the effort of the consonant will be strongest when the vowels and consonant share some primary articulator, i.e. lips, tongue tip, or tongue body, most commonly the latter (an effect manifested in the ubiquitous phenomenon of CV coarticulation, which indeed is most dramatic in dorsal consonants, cf. Flemming 1997); but even in the absence of a shared primary articulator, the consonant and vowels both involve the jaw. In this "least common denominator" case, then, the displacement-vs.-time curve may be taken to refer to jaw movement.
} 


\begin{tabular}{|c|c|c|c|c|}
\hline & & $\mathrm{LAZY}_{\geq \mathrm{x}+1}$ & PRES(cont) & $\mathrm{LAZY}_{\geq \mathrm{x}}$ \\
\hline b->b/r_i & (fast rate) & *!! & & * \\
\hline $\mathrm{b}->\mathrm{w} / \mathrm{r} \_\mathrm{i}$ & (fast rate) & & $*$ & $*$ \\
\hline $\mathrm{b}->\mathrm{b} / \mathrm{r} \_\mathrm{i}$ & (normal rate) & & & * \\
\hline $\mathrm{b}->\mathrm{w} / \mathrm{r} \_\mathrm{i}$ & (normal rate) & & $* !$ & \\
\hline
\end{tabular}

Assuming that $[\mathrm{b}]$ in the context $/ \mathrm{r}_{\text {_ }} \mathrm{i}$ involves effort $\geq x+1$ in fast speech (though not in normal speech), under the same ranking as (30), we obtain the result that lenition in a particular context is triggered in fast speech but not at normal rates. Register, though distinct from rate, has the same effect on speech with respect to lenition (e.g. Zwicky 1971, Donegan \& Stampe 1979, Lindblom 1983, 1990). The effect of register lowering on articulatory reduction can be modeled in terms of a numerical index $i$, part of the input to phonological computation, which is added to the base effort cost of the candidate gestures: the lower the register, the higher the value of $i .^{27}$

\begin{tabular}{|l||c||c|c|c|}
\hline (all at normal speech rate) & LAZY $_{\geq \mathrm{x}+1}$ & PRES(cont) & LAZY $\geq \mathrm{x}$ \\
\hline \hline $\mathrm{b}->\mathrm{b} / \mathrm{r} \_\mathrm{i}$ & (low register, $i=1)$ & $* !$ & & $*$ \\
\hline $\mathrm{b}->\mathrm{w} / \mathrm{r} \_\mathrm{i}$ & (low register, $i=1)$ & & $*$ & $*$ \\
\hline \hline $\mathrm{b}->\mathrm{b} / \mathrm{r} \_\mathrm{i}$ & (high register, $i=0)$ & & & $*$ \\
\hline $\mathrm{b}->\mathrm{w} / \mathrm{r} \_\mathrm{i}$ & (high register, $i=0)$ & & $* !$ & \\
\hline
\end{tabular}

At the normal speech rate, $[\mathrm{b}]$ in the context $/ \mathrm{r}_{\mathrm{L}} \mathrm{i}$ involves a base effort cost below $x+1$, but when augmented by $i$ in low register (where $i=1$ ), the adjusted effort cost is now greater than or equal to $x+1$. Thus, with the same ranking of effort thresholds, we obtain the result that lenition in a particular context at a particular rate is triggered in casual speech but not in a higher register, just as it is at faster rates. ${ }^{28}$

2.2.5. RELATION TO LOCAL ASSIMILATION PHENOMENA. Finally, this constraint system is motivated not merely by lenition phenomena: essentially the same system is deployed by Jun 1995 to handle place assimilation in consonant clusters. Jun demonstrates that casual speech gradient assimilation (e.g. English /fon $\mathrm{b}_{\mathrm{k}} \mathrm{k} / \mathrm{->}$ [fomb $\mathrm{k}$ ]), attributed by Browman and Goldstein (1990) to gestural overlap, in fact involves gestural reduction of $\mathrm{C}_{1}$, to the point where the percept

${ }^{27}$ Cf. Lindblom's (1990) notion of an across-the-board hypoarticulation parameter.

${ }^{28}$ Effort-based lenition environments (e.g. intervocalic and post-vocalic) which are insensitive to rate and register variation pose a non-trivial problem for this approach. A possible treatment of such patterns, involving an extension of the notion of paradigmatic faithfulness (cf. section 5 below) is sketched in Kirchner (in progress). 
of $\mathrm{C}_{1}$ 's place of articulation is lost; moreover, categorical "phonological" assimilations can be analyzed in the same terms, where the reduction of the $\mathrm{C}_{1}$ gesture is total. Local assimilations, ${ }^{29}$ then, emerge as a special case of lenition, where gestural reduction is accompanied by temporal extension of the gesture of $\mathrm{C}_{2}$, in order to preserve other underlying properties of the target segment, such as non-continuancy.

$>$\begin{tabular}{|l||c|c|c|c|}
\hline /atka/ & MAX & IDENT(cont) & LAZY & IDENT(cor) \\
\hline \hline atka & & & $* * * * !$ & \\
\hline akka & & & $* * *$ & $*$ \\
\hline ahka & & $* !$ & $* *$ & $*$ \\
\hline aka & $* !$ & & $*$ & \\
\hline
\end{tabular}

It can readily be inferred from (33) that, with higher ranking of LAZY, the manner as well as the place of the underlying / $/$ / would be lost, resulting in debuccalization or elision. In sum, Optimality Theoretic conflict between articulatory and perceptual imperatives (i.e. LAZY vs. the faithfulness and fortition constraints) appears to offer insight into a broad range of sound patterns.

\section{GEMINATES AND LENITION}

3.1. EFFORT IN GEMINATES. In this section, I motivate a set of effort relations between geminates and possible lenited correspondents.

3.1.1. Degemination. Under the mass-spring model described in section 2.2.1, the result emerges that geminate stops are more effortful than singleton stops:

\footnotetext{
${ }^{29}$ Harmonic (long-distance) assimilations appear to be perceptually driven, see e.g. Kaun 1994.
} 
(34)
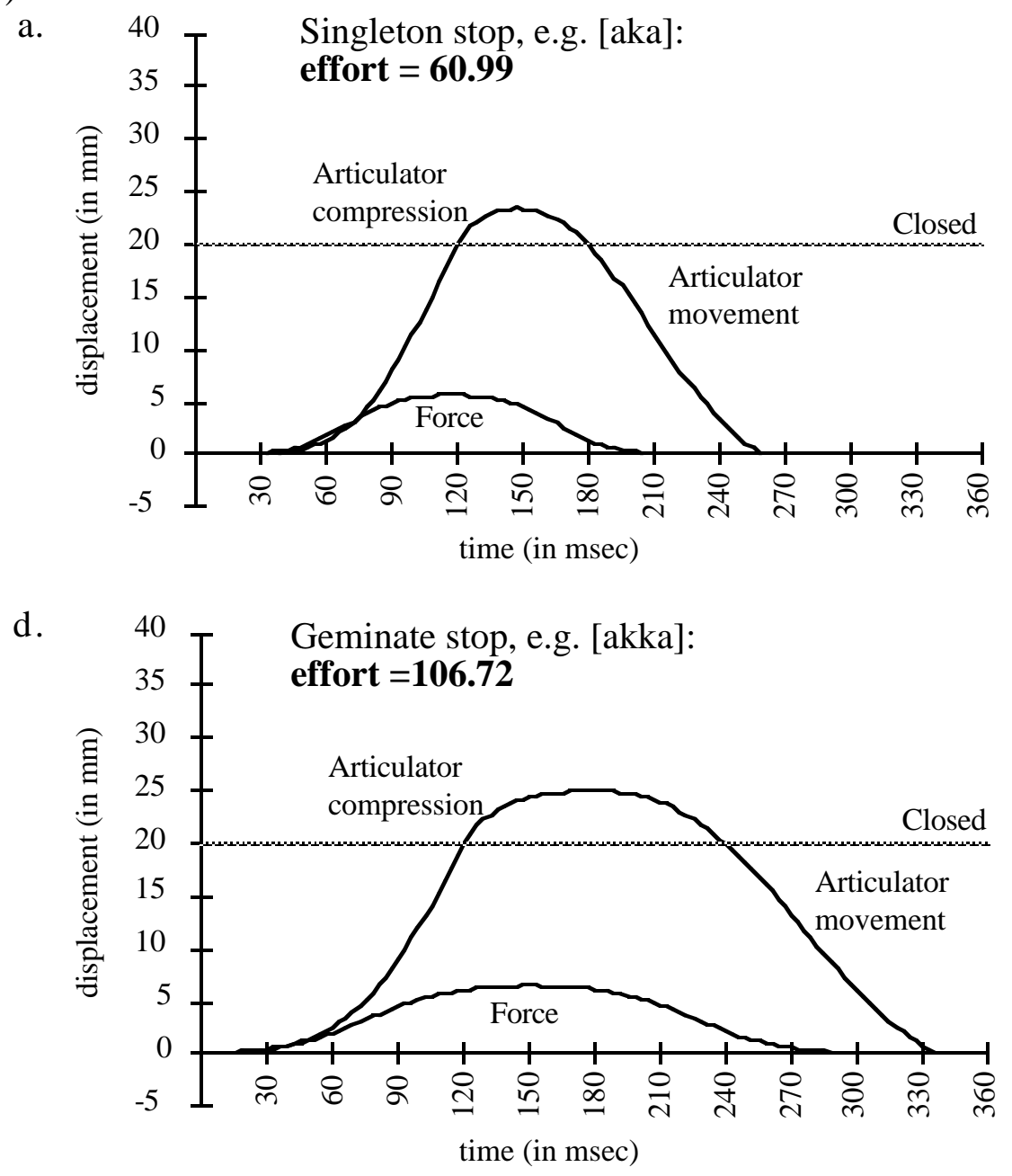

Let [length] informally denote the property that distinguishes geminates from singletons, however this is to be formally represented (featurally, segmentally, or moraically). Now, degemination obtains under the ranking LAZY » IDENT(length).

\begin{tabular}{|l||c|c|}
\hline Input: akka & LAZY & IDENT(length) \\
\hline \hline akka & $* * !$ & \\
\cline { 2 - 4 } aka & $*$ & $*$ \\
\hline
\end{tabular}

The treatment of degemination is thus unified with the general effort-based approach to lenition outlined in section 2.2.

3.1.2. REDUCTION OF ORAL CONSTRICTION. Recall from section 2 that spirantization is treated as reduction of a stop gesture, for reasons of effort minimization, to the point that closure is 
lost. Unlike the sort of brief fricative constriction shown in (36a), ${ }^{30}$ however, geminate fricatives, and more broadly, geminate continuant consonants, involve a prolonged steady-state constriction, by definition (36b):

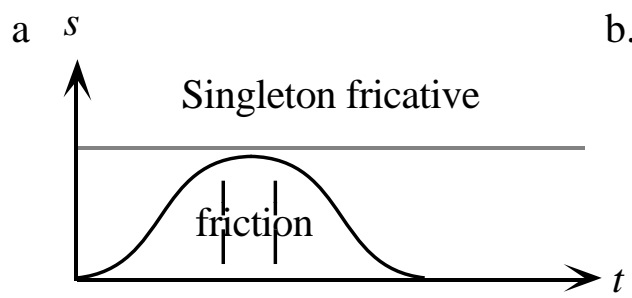

b. $s$

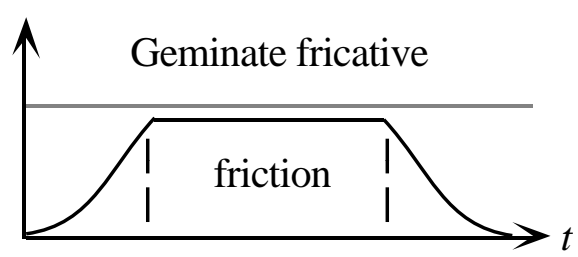

To achieve this prolonged steady-state constriction, I assume that the upward movement of the active articulator must be arrested by an active antagonistic force applied to the same articulator, i.e. isometric tension. This assumption is supported by the mass-spring model, which is able to achieve a geminate fricative only by opposing the positive force impulse with a substantial amount negative force:

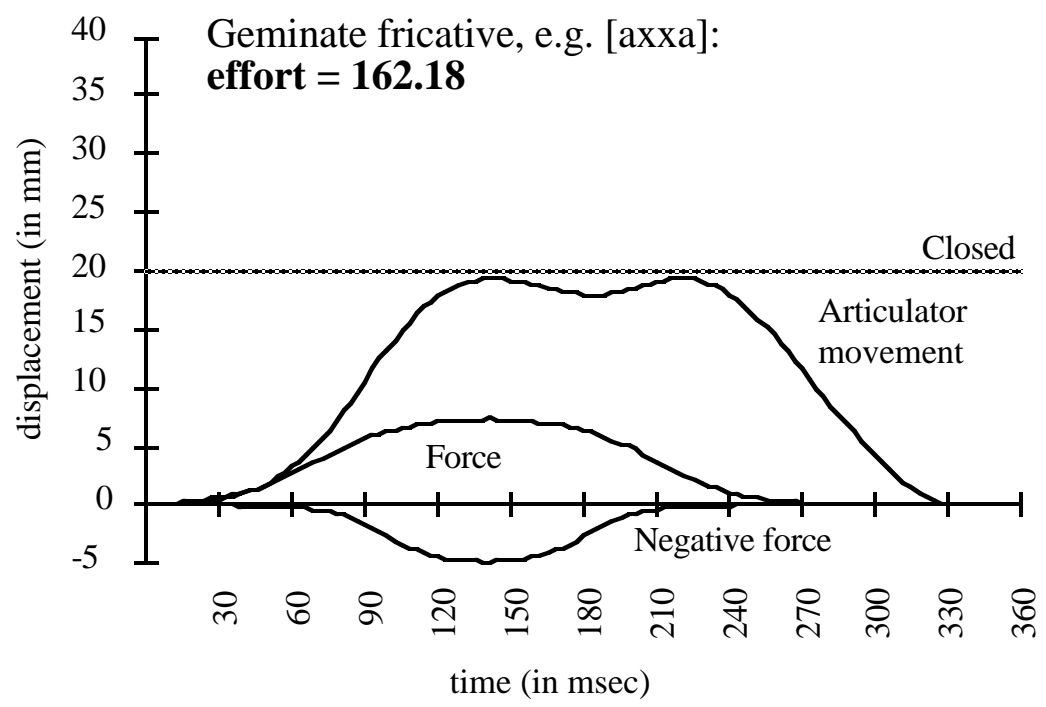

By comparison, under the mass-spring model, the geminate stop (and all the singleton consonants) require no such negative force, with the result that the geminate fricative emerges as more effortful than the geminate stop, or any of the singletons (compare (37) with (24) and (34)).

${ }^{30}$ See fn. 22. 
3.1.3. HALF-SPIRANTIZATION AND PARTIAL GEMINATES. For similar reasons, halfspirantization of a geminate stop also increases its effort cost. This assumption is supported by the mass-spring model:

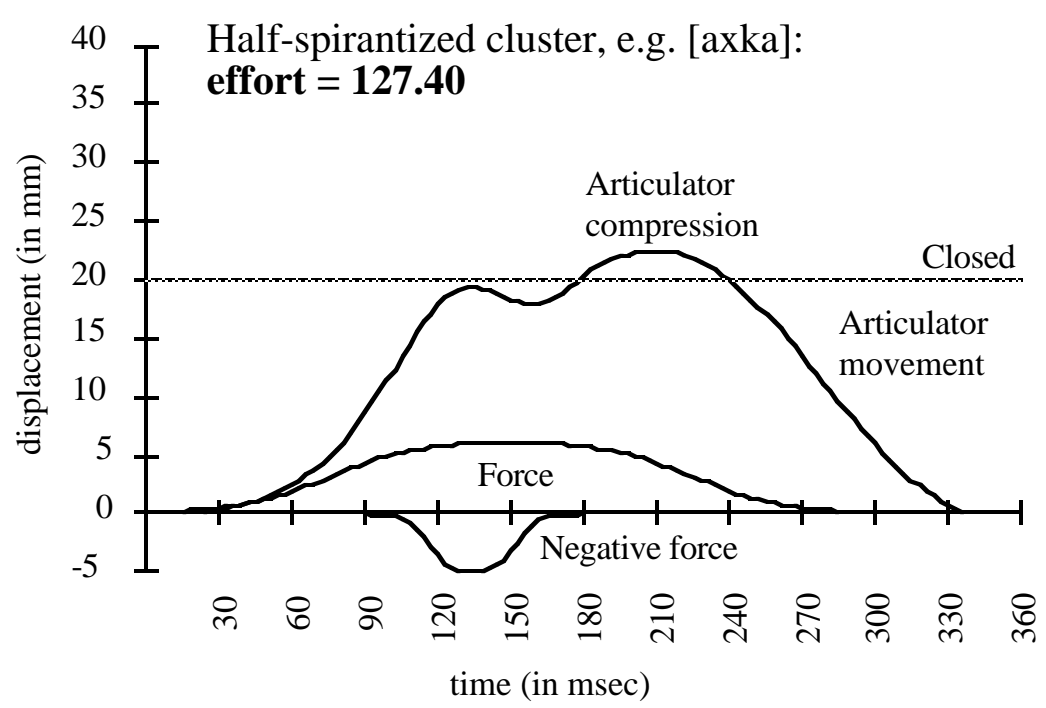

Note, however, that the "problem" in the half-spirantized gesture necessitating isometric tension is the steady-state constriction of the fricative. If the lenited portion of the geminate does not involve a steady-state constriction (e.g. the glide + homoganic stop clusters of Maxakalí, see section 1.2.5), we can obtain this result simply by slowing down the transition into the closure, as shown in (39).

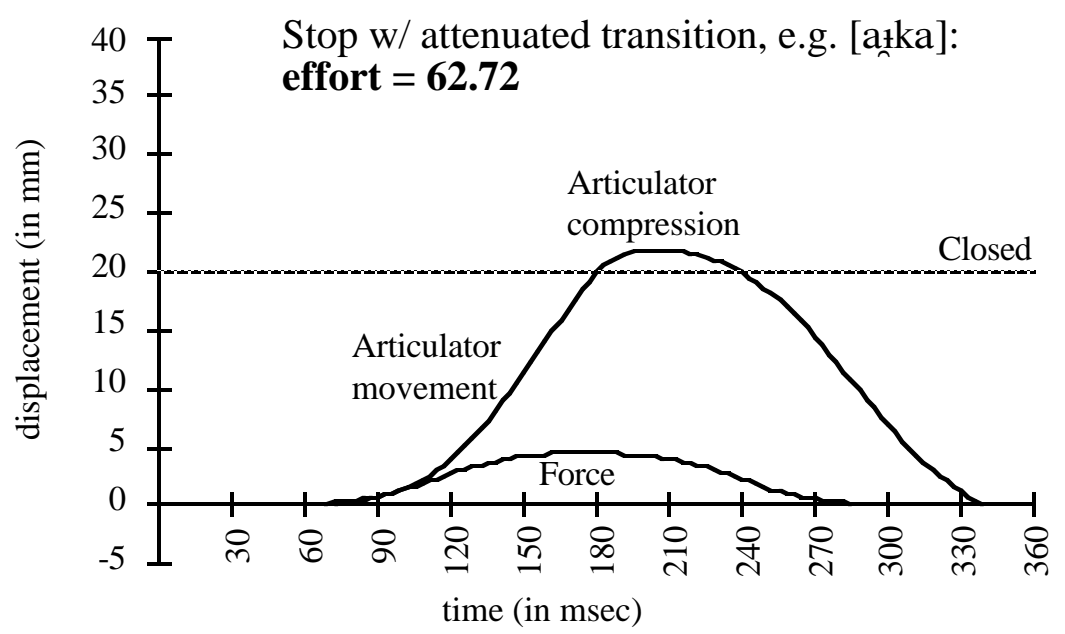


Note that the foregoing conclusions concerning spirantization and half-spirantization of geminate stops apply equally to partial geminates. For the effort relations above refer to oral constriction gestures; and, as schematized in (40), the oral constriction of a partial geminate is equivalent to that of a full geminate.

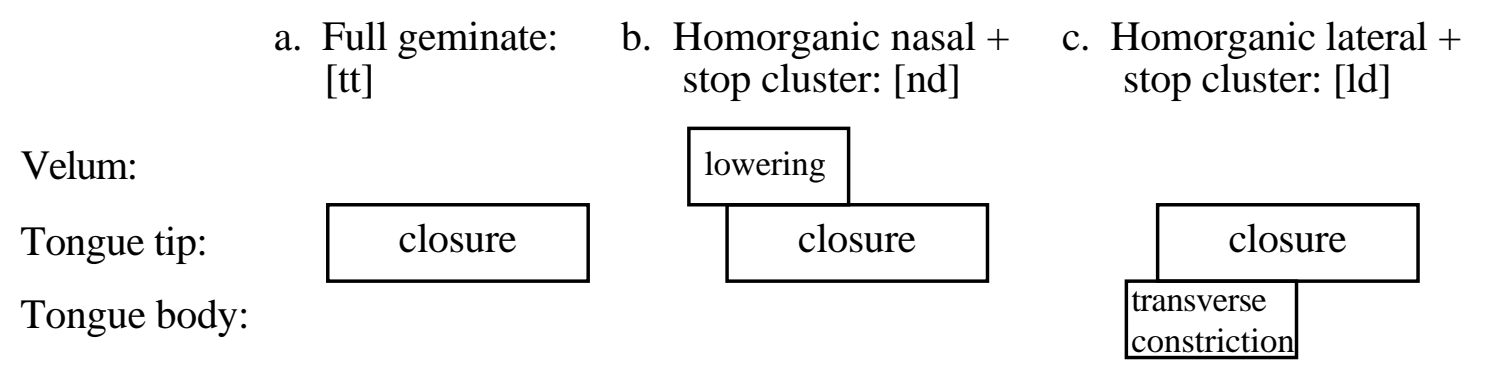

\subsubsection{VOICING}

3.1.4.1. STOPS. Ohala 1983 identifies a straightforward aerodynamic explanation for the markedness of geminate voiced stops, namely their tendency to passively devoice. As air pressure builds up in the oral cavity during a stop, the trans-glottal air pressure differential drops below what is required to keep the vocal folds vibrating (roughly 2,000 dyne/cm ${ }^{2}$ ), and voicing ceases, typically $60 \mathrm{msec}$ into the closure for an alveolar stop (slightly earlier for a velar, and later for a labial) (Westbury and Keating 1986). Voicing can be extended during an oral stop by various cavity expansion gestures, e.g. pharynx expansion and larynx lowering (Rothenberg 1969). ${ }^{31}$ However, to sustain voicing for the duration of a geminate, typically over $150 \mathrm{msec}$., "heroic" cavity expansion is required, which necessarily involves additional effort.

\footnotetext{
${ }^{31}$ The other principal strategy of avoiding passive devoicing, "nasal leak," carries a perceptual cost: risking confusion of the stop with a nasal consonant.
} 


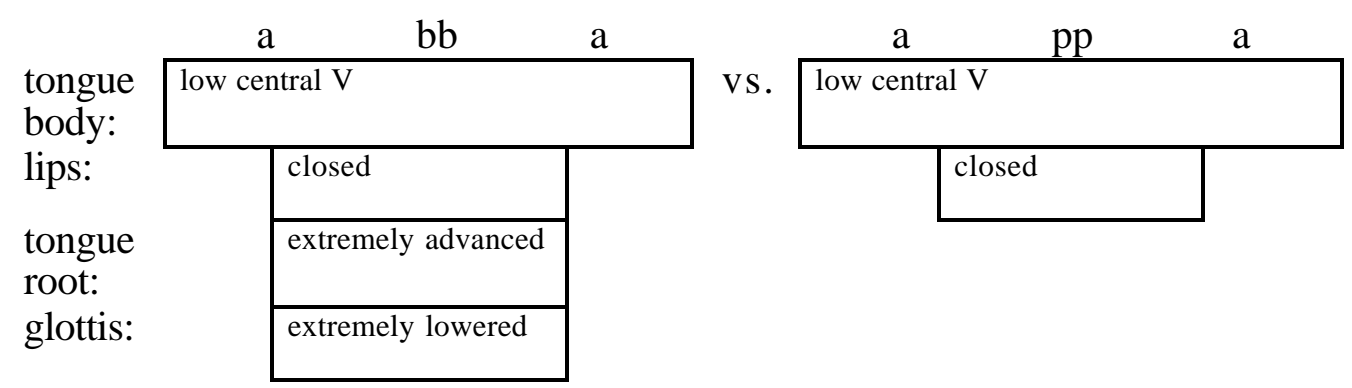

Consequently,

(42) Voiced geminate stop $>_{\text {effort }}$ (Substantially) voiceless geminate stop

(the reverse of the situation in medial singletons).

Note, however, that partial geminates present none of these devoicing problems. For the air is vented during the nasal or lateral portion of a partial fricative, preventing significant build-up of oral pressure. Indeed, Hayes \& Stivers (in progress) show that the velic raising that occurs toward the end of a nasal + stop cluster actually facilitates voicing, by expanding the oral cavity during the oral portion of the cluster.

3.1.4.2. FriCATIVES. Geminate fricatives likewise tend to passively devoice. My own simulations, using the analog circuit model of vocal tract aerodynamics described in Westbury \& Keating 1986, show that with a close fricative (oral aperture $=20 \mathrm{~mm}^{2}$ ), passive devoicing occurs (i.e. the transglottal pressure differential falls below 2,000 dyne/ $\mathrm{cm}^{2}$ ) at $95 \mathrm{msec}$ in an alveolar. With a more open fricative $\left(30 \mathrm{~mm}^{2}\right),{ }^{32}$ the point of passive devoicing is postponed to $166 \mathrm{msec}$ for an alveolar, too late to account for devoicing in a geminate fricative; and indeed labials appear never to reach the point of passive devoicing. However, this assumes that the glottal aperture of a voiced fricative is equivalent to that of a voiced stop (estimated at $4 \mathrm{~mm}^{2}$ by Westbury \& Keating, averaging over vibratory cycles). In fact, Ohala 1983 observes that the glottis is typically somewhat more abducted in a voiced fricative than it is in a voiced stop. This is because fricatives crucially involve a pressure differential at the place of oral constriction (as well as at the glottis, if voiced):

${ }^{32}$ Clark \& Yallop 1990:84 indicate that $30 \mathrm{~mm}^{2}$ is a plausible upper bound on oral aperture in fricatives. 


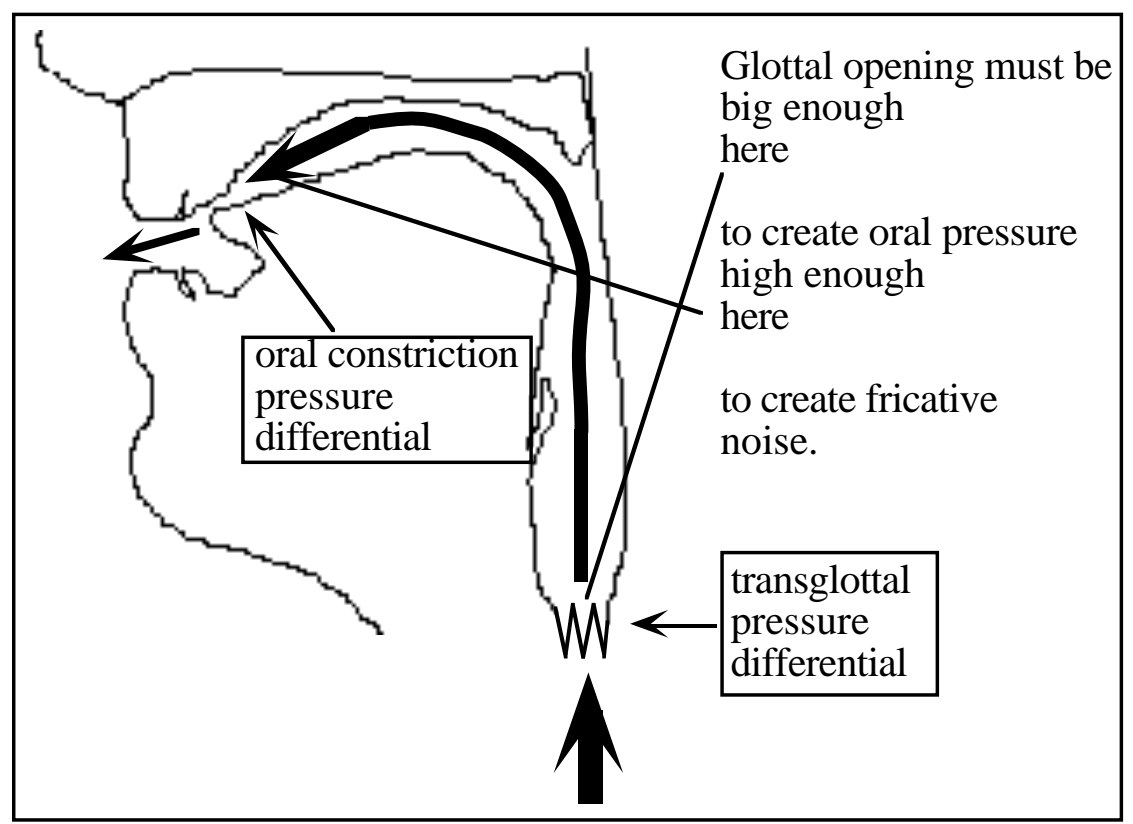

With an increase in glottal aperture of just $1.5 \mathrm{~mm}^{2}$, the build-up of oral pressure, hence passive devoicing, occurs much earlier. ${ }^{33}$ The results are summarized in Table 6.

Table 6: Point of passive devoicing, medial geminate fricative, in msec. Oral aperture $=20 \mathrm{~mm}^{2}$ Oral aperture $=30 \mathrm{~mm}^{2}$

\begin{tabular}{|c|c|c|c|c|c|c|}
\hline & 125 (lab) & 95 (alv) & 85 (vel) & $--(\mathrm{lab})$ & 166 (alv) & 127 (vel) \\
\hline & b) & 89 (alv) & 80 (vel) & 117 (lab) & (alv) & el) \\
\hline
\end{tabular}

Thus, a substantial portion of the geminate fricative is devoiced, even if the fricative is quite open, unless cavity expansion gestures or other heroic voicing strategies are employed, just as in geminate stops. We may therefore conclude that:

(44) Voiced geminate fricative > effort (Substantially) voiceless geminate fricative

3.1.4. SUMmary. The effort relations motivated above can be presented in the form of a Hasse diagram, which conveys the additional relations which follow from transitivity:

\footnotetext{
${ }^{33}$ The slight abduction assumed here is still a long way from a truly spread glottis (e.g. in actively devoiced stops), estimated at $32.5 \mathrm{~mm}^{2}$ by Westbury \& Keating.
} 


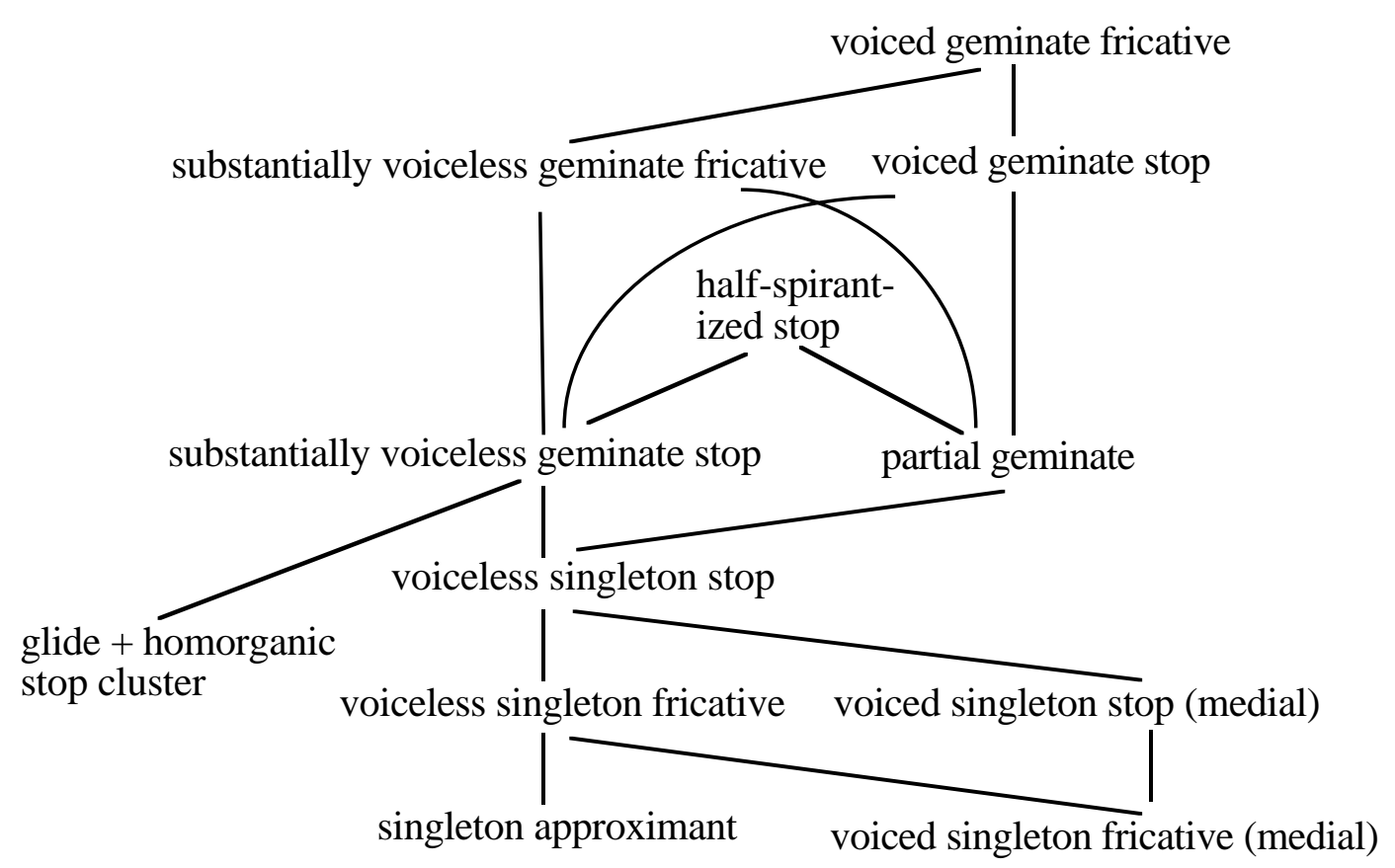

\subsection{A FORMAL ACCOUNT OF THE GEMINATE LENITION GENERALIZATIONS}

3.2.1. NO ORALLY REDUCED GEMINATES, ETC. Recall that geminate continuants are more effortful than geminate stops (section 3.1.2). Now, no ranking of IDENT(cont) and LAZY allows an input stop (geminate or otherwise) to map to an output geminate continuant, since the latter candidate fares worse than a geminate stop with respect to both constraints.

$>$\begin{tabular}{|l||cc|}
\hline apcp)a & LAZY & IDENT(cont) \\
\hline \hline appa & $*$ & \\
\hline a $\phi \mathrm{a}$ & $* *$ & $*$ \\
\hline
\end{tabular}

An input geminate stop can only yield a spirantized output if the output degeminates as well.

\begin{tabular}{|l||c|cc|}
\hline appa & LAZY & IDENT(cont) & IDENT(length) \\
\hline \hline appa & $* * !$ & & \\
\hline $\mathrm{a} \phi \phi \mathrm{a}$ & $* * * !$ & $*$ & \\
\hline $\mathrm{a} \mathrm{Fa}$ & $*$ & $*$ & $*$ \\
\hline
\end{tabular}

Likewise, because of the effort relations \{Geminate fricative, Half-spirantized stop\} > \{Geminate stop, Partial geminate\} (section 3.1.3), neither full nor partial geminates can undergo 
spirantization or half-spirantization (modulo the heteromorphemic geminate case considered in section 4).

\begin{tabular}{|c|c|c|}
\hline \multirow[b]{2}{*}{ арpa -> appa } & LAZY & IDENT(cont) \\
\hline & * & \\
\hline appa -> афра & $* *$ & $*$ \\
\hline ampa -> ampa & $*$ & \\
\hline ampa -> amфа & ** & * \\
\hline ampa -> aw $\phi a$ & $* *$ & $*$ \\
\hline
\end{tabular}

In sum, since reduction of oral constriction in geminate stops increases the effort cost, due to the increased isometric tension involved (see sections 3.1.2, 3.1.3), oral reduction of geminates is ruled out universally, and the NO ORALLY REDUCED GEMINATES, NO HALF-SPIRANTIZATION, and NO REDUCTION OF PARTIAL GEMINATES generalizations are captured. No process converts a consonant (geminate or otherwise) to a geminate with reduced oral constriction. No process converts a (tautomorphemic) geminate stop to a "half-spirantized" cluster, e.g. /kk/-> *[xk]. "Partial geminates" (i.e. homorganic nasal + stop or lateral + stop clusters) behave identically to full geminates with respect to reduction of oral constriction.

3.2.2. VOICING. By precisely the same reasoning (see section 3.1.4), voicing of geminate obstruents is prohibited, and the NO VOICING OF GEMINATES generalization is captured.

$>$\begin{tabular}{|l||cc|}
\hline & LAZY & IDENT(voi) \\
\hline \hline appa -> appa & $*$ & \\
\hline appa $->$ abba & $* *$ & $*$ \\
\hline
\end{tabular}

No process converts a voiceless segment (geminate or otherwise) to a voiced geminate obstruent.

3.2.3. OCCLUSIVIZATION, DEVOICING. In singletons, occlusivization processes must be attributed to fortition constraints. If such a constraint is active in some grammar, it must outrank IDENT(cont). (It must also outrank LAZY, or more precisely, that degree of LAZY violated by stops in the context in which the occlusivization occurs.) 


$>$\begin{tabular}{|l||c|cc|}
\hline Input: $\phi$ & $*[+$ cont $] / \mathrm{K}$ & IDENT(cont) & $\operatorname{LAZY}_{X}$ \\
\hline \hline $\mathrm{p}$ in context $\mathrm{K}$ & & $*$ & $*$ \\
\hline$\phi$ in $\mathrm{K}$ & $* !$ & & \\
\hline
\end{tabular}

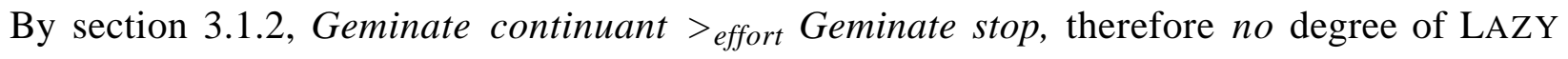
favors the fricative geminate. And since the fortition constraint must outrank IDENT(cont), the only constraint which potentially blocks occlusivization, it follows that the geminate must occlusivize as well.

$>$\begin{tabular}{|l||c|c|}
\hline Input: $\phi \phi$ & $*[+$ cont $] / \mathrm{K}$ & IDENT(cont) \\
\hline \hline pp in context $\mathrm{K}$ & & $*$ \\
\hline$\phi \phi$ in $\mathrm{K}$ & $* !$ & \\
\hline
\end{tabular}

\begin{tabular}{|c|}
\hline LAZY \\
\hline \hline$*$ \\
\hline$* *$ \\
\hline
\end{tabular}

(LAZY is split off from the rest of the tableau above to indicative that its ranking relative to the other constraints does not affect the result here.) By the same reasoning (see section 3.1.4), the same result obtains for geminate devoicing.

$>$\begin{tabular}{|l||c|c|}
\hline Input: $\mathrm{bb}$ & $*$ [+voi] / K & IDENT(voi) \\
\hline \hline pp in context K & & $*$ \\
\hline $\mathrm{bb}$ in $\mathrm{K}$ & $* !$ & \\
\hline
\end{tabular}

\begin{tabular}{|c|}
\hline LAZY \\
\hline \hline$* *$ \\
\hline$* *$ \\
\hline
\end{tabular}

Consequently, the NO EXCLUSIVE OCCLUSIVIZATION OR DEVOICING OF SINGLETONS generalization is captured. No occlusivization nor obstruent devoicing process targets singletons to the exclusion of geminates. In contrast, occlusivization or devoicing of geminates (e.g. Berber, Schein \& Steriade 1986) obtains under any ranking in which the LAZY (or more precisely, that degree of LAZY violated by geminate continuants or voiced geminate obstruents, respectively) or the relevant fortition constraint, dominates IDENT(cont) or IDENT(voi), respectively.

3.2.5. INVENTORY ASYMMETRIES. As shown in the previous section, to obtain surface geminate continuants or voiced geminate obstruents, IDENT(cont) or IDENT(voi) must dominate the relevant degree of LAZY, and any applicable fortition constraints (otherwise occlusivization or devoicing will occur): 


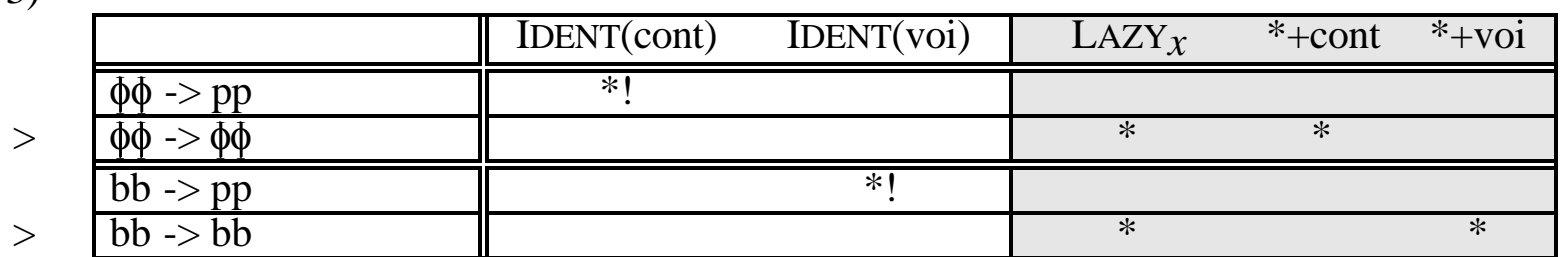

But under this ranking, an input geminate stop, or voiceless geminate obstruent, surfaces unchanged (and such inputs must be allowed, by the OT tenet of Richness of the Base):

\begin{tabular}{|c|c|c|c|c|c|}
\hline \multirow[b]{2}{*}{$\mathrm{pp}$} & IDENT(cont) & IDENT(voi) & $\operatorname{LAZY}_{x}$ & $*+\mathrm{cont}$ & *+Voi \\
\hline & & & & & \\
\hline$p p->\phi \phi$ & *! & & * & * & \\
\hline $\mathrm{pp}->\mathrm{bb}$ & & *! & $*$ & & * \\
\hline
\end{tabular}

Consequently, the INVENTORY ASYMMETRIES generalization is captured. The presence of $a$ geminate continuant consonant, or voiced geminate obstruent, in the segment inventory of a language (whether derived or underlying) implies the presence of a corresponding noncontinuant or voiceless geminate, respectively.

\section{HETEROMORPHEMIC GEMINATES}

In section 3.2.3 the effort-based approach appears to rule out half-spirantization of geminates. Yet in the discussion of Tigrinya in section 1.2.2, we have seen that half-spirantization is indeed possible, provided that the geminates are heteromorphemic. The Tigrinya facts were taken by Hayes 1986 as precluding any sort of phonetically-based account of geminate inalterability. If inalterability is attributed to phonetic considerations, how, then, could heteromorphemic and tautomorphemic geminates (which are typically phonetically indistinguishable) behave differently from one another? The answer lies in OT's capacity for interaction between purely articulatory constraints such as LAZY and constraints which do refer to morphological affiliation.

Specifically, a class of paradigmatic faithfulness constraints (also called output-output faithfulness, uniform exponence, paradigm uniformity, and allomorphy minimization constraints) has been motivated by such phenomena as base-reduplicant correspondance, base-derivative 
correspondance in truncation patterns, and cyclicity effects, see Benua 1995, 1997; Flemming 1995; Kenstowicz 1995; McCarthy and Prince 1995; Steriade 1996; Burzio 1997. These constraints are formally similar to the input-output faithfulness constraints employed in sections 2 and 3 above, but the comparison is between two morphologically related surface forms, typically a base and its derivative. Unlike input-output faithfulness, these paradigmatic constraints can enforce identity between output and base with respect to phonologically derived surface properties of the base, including lenition.

The Tigrinya pattern of half-spirantization of heteromorphemic geminates now follows from the ranking in (55):

\begin{tabular}{|l||c|c|c|}
\hline $\begin{array}{l}\text { Input: } / \text { mIrak-ka/ } \\
\text { (base }=[\text { mIrax] }\end{array}$ & $\begin{array}{c}\text { IDENT(BASE/ } \\
\text { DERIVATIVE, cont) }\end{array}$ & LAZY & IDENT(I/O, cont) \\
\hline \hline mIrakka & $* !$ & $*$ & \\
\hline mIraxka & & $* *$ & $*$ \\
\hline
\end{tabular}

That is, spirantization occurs in [mrraxka] not because it serves the goal of effort minimization (in fact, it fares worse on this score than the competing candidate [mirakka]), but because it promotes similarity between the output and its base, [mrrax], in which spirantization is motivated by LAZY. If, however, IDENT(BASE/DERIVATIVE, cont) is subordinated to LAZY, heteromorphemic geminates will be inalterable under spirantization, just like tautomorphemic geminates, as we find Tiberian Hebrew. Finally, in tautomorphemic geminates, paradigmatic concerns do not enter the picture (there can be no separate base containing a spirantized singleton), and so half-spirantization is ruled out under any ranking, as discussed in section 3.2.1.

It is thus possible to account for the distinct inalterability behavior of hetero- and tautomorphemic geminates within a phonetically-based approach, pace Hayes. Nor does this treatment require us to reify this distinction in morphological affiliation in terms of a phonetically unmotivated representational distinction between "true" (multiply-linked) and "fake" (singlylinked) geminates (cf. section 5.1). 


\section{ALTERNATIVE TREATMENTS}

5.1. The Classic InAlterability PROpOSAlS. Both Hayes 1986 and Schein \& Steriade 1986 attempt to derive geminate inalterability effects largely from general assumptions of the theory of representations of Autosegmental Phonology (e.g. Goldsmith 1976, Clements and Keyser 1983).

(56) a. True geminate: $X X$ Melody

b. Singleton: $\mathrm{X}$

c. Heteromorphemic geminate: $\mathrm{X}+\mathrm{X}$ Melody Mel. Mel.

In particular, "true" geminates (56a) can be distinguished from both singletons (b) and heteromorphemic ("fake") geminates (c), in that true geminates involve multiple association of the melody (featural content of the segment) to the segment-timing or prosodic units which dominate it. Hayes attributes inalterability to the following notational convention:

Linking Constraint. Association lines in structural descriptions are interpreted as exhaustive.

Thus, a rule such as Tigrinya spirantization (58a) cannot apply to a geminate, because the structural description of the rule refers to a single association line between the target dorsal consonant and its timing unit, whereas a geminate is associated with two timing units (65b).

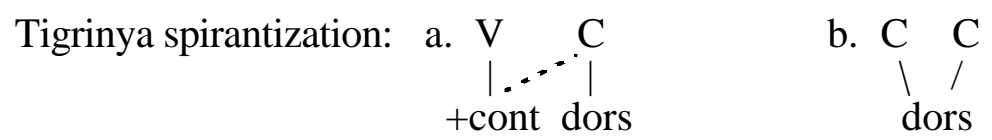

Schein \& Steriade propose a somewhat more narrowly drawn convention:

(59) Uniform Applicability Condition ("UAC"). Given a node $n$, a set $\mathrm{S}$ consisting of all nodes linked to $n$ on some tier $\mathrm{T}$, and a rule $\mathrm{R}$ that alters the contents of $n$ : a condition in the structural description of $\mathrm{R}$ on any member of $\mathrm{S}$ is a condition on every member of $\mathrm{S}$.

The principal difference between the two conventions is that the Linking Constraint blocks rule application when the target or trigger is a geminate; whereas the UAC blocks only when the target is a geminate, by virtue of the "alters the contents" clause. However, both approaches focus upon the representational distinction between single and multiple autosegmental association to block 
certain rules from applying to geminates. Furthermore, both approaches elegantly handle the distinct behavior of tauto- and heteromorphemic geminates, e.g. in Tigrinya, where the first half of heteromorphemic geminates undergo spirantization, just like singletons (see section 1.2.2): heteromorphemic geminates are singly linked (56c), just like singletons (b).

Neither approach, however, draws a connection between inalterability and lenition phenomena. Neither approach prohibits rules which specifically target geminates for full or partial spirantization or voicing. And neither approach draws a connection between inalterability effects and the general markedness of geminate continuant consonants and geminate voiced obstruents, as reflected in segment inventories. Rather, these approaches predict that inalterability effects are tied to what Schein \& Steriade call "structure-dependent" rules, which refer to information on both melodic and timing-unit tiers. Such rules necessarily refer to the linkages between these tiers, thus invoking blocking by the Linking Constraint or UAC. Inkelas \& Cho 1993, however, demonstrate that this prediction is false. Syllabification processes (whether formalized in terms of rules or constraints, cf. Itô 1986) refer to prosodic and melodic information, and thus should invariably display inalterability effects. ${ }^{34}$ Yet in Korean, for example, the rule or constraint which eliminates velar nasals in onset position applies to singletons and geminates alike (e.g. [kay] ('river'), but *[ana], *[anja]). Similarly, geminates are never immune to rules or constraints requiring sonority sequencing within coda and onset clusters: thus in Latin, a coda [kl] cluster is ill-formed, whether the [1] is a singleton (e.g. *[akl.ta]) or the first half of a geminate (e.g. *[akl.la]). Inkelas \& Cho further note that the Linking Constraint and UAC do not hold true for "long-distance" (i.e. segmentally non-adjacent) multiple linking, as both Hayes and Schein \& Steriade acknowledge. For example, tones which are associated to multiple syllables are not typically immune to processes affecting singly-linked tones.

Finally, Inkelas \& Cho observe that it is frequently possible to formulate rules either as structure-dependent or segmental, so as to place the rule within or outside the purview of the Linking Constraint or UAC; thus, the predictions these approaches make, as to which processes

${ }^{34}$ Indeed Itô (1986) relies upon the Linking Constraint to account for geminates' immunity to a phonotactic coda place constraint in Japanese and other languages. 
will or will not exhibit geminate inalterability effects, are not as strong as initially meets the eye (as Hayes (p. 344) acknowledges). ${ }^{35}$ Indeed, this criticism can be taken considerably further: to the extent that these approaches attempt to constrain possible individual rules, without thereby constraining sound systems, they are empirically vacuous. Thus, for example, nothing in these approaches rules out "Zigrinya," a hypothetical language with a general post-vocalic spirantization rule, as in Tigrinya, plus a rule specifically spirantizing post-vocalic geminates. Zigrinya thus achieves by a combination of licit rules the same unattested sound pattern which the Linking Constraint and UAC purport to rule out.

5.2. GENERALIZED INALTERABILITY. In contrast to the foregoing approaches, Inkelas \& Cho 1993 challenge the basic assumption that geminate inalterability is a discrete phenomenon. Inkelas \& Cho observe that the blocking of phonological rules is not a phenomenon confined to geminates. For example, the "opaque" behavior of certain vowels in harmony processes, and lexical exceptionality, are also examples of rule blocking. They further identify prespecification as the generalized blocking mechanism, and predict that it is the class of feature-filling rules which systematically display inalterability effects (whether geminate inalterability, or other blocking phenomena). For example, under their analysis, Latin coda [1] velarization involves a rule assigning onset [1] a [-back] specification. This rule applies to the geminates, because they are in onset position (it does not matter that they are also in coda position). Other (i.e. coda singleton) laterals undergo a context-free feature-filling rule making laterals [+back]. The onset rule is ordered before the context-free rule, by virtue of the Elsewhere Condition (Anderson 1969, Kiparsky 1973). But the context-free rule is blocked from applying to the geminates (or other onset [1]'s), because they are already specified for [back]. Other prespecifying rules may specifically target geminates: e.g. in Berber, a rule specifies geminate consonants as [-cont], which bleeds an "elsewhere" rule assigning [+cont].

\footnotetext{
${ }^{35}$ For example, Schein \& Steriade analyze Turkish depalatalization as changing a coda velar to [+back], thereby invoking the UAC, and correctly accounting for the fact that this depalatalization does not affect a multiply-linked [-back] specification. However, it is equally possible (and, as Inkelas \& Cho argue, more elegant) to express this as a rule delinking a [-back] specification from a coda velar; this delinking rule does not invoke the UAC, since it does not "alter the contents" of the multiply-linked node.
} 
Despite their heavy reliance on rule ordering and underspecification, Inkelas \& Cho's notion of blocking through prespecification translates rather neatly into OT, as blocking through higher-ranked constraints (cf. the discussion of blocking and triggering in Prince \& Smolensky 1993, chs. 3-4). For example, Inkelas \& Cho's analysis of Latin [1] velarization can be restated as follows:

ONSET L: *[+back,+lateral $]$ in onset

$>$\begin{tabular}{|l||c|c|}
\hline & ONSET L & ELSEWHERE L \\
\hline \hline al.la & & $*$ \\
\hline a:.ra & $* !$ & \\
\hline \hline al.ta & & $* !$ \\
\hline ai.ta & & \\
\hline
\end{tabular}

ONSET L » ELSEWHERE L, by Panini's Theorem (the OT equivalent of the Elsewhere Condition), Prince \& Smolensky 1993, ch. 5.

But while Inkelas \& Cho's approach, particularly in its OT reincarnation, gives us a general mechanism for the blocking of phonological processes, it does not account for the generalizations identified in section 1, which specifically concern geminates and lenition. Inkelas \& Cho, acknowledging Churma's (1988) observations along these lines, attempt to draw a connection between geminate inalterability and lenition, as follows. They assume, following Hyman 1985 and Hayes 1989, that (underlying) geminates are linked to moras in underlying representation; whereas other segments must be assigned moras by rule. Moraification rules often impose minimum sonority requirements on coda consonants, e.g. Hausa (Table 1), which requires codas to be [+sonorant]. The geminates escape this condition of the moraification rule, however, because they are already moraified. However, this analysis only extends to cases of coda lenition. In Tigrinya and Hebrew, geminate inalterability effects are observed, although lenition occurs in intervocalic onset, as well as coda, position (i.e. post-vocalically). For these sorts of cases, Inkelas \& Cho must stipulate that a rule specifying geminates as [-cont] has priority over a rule specifying post-vocalic obstruents as [+cont] (Elsewhere Condition ordering does not obtain, as there is no subset relation between the structural descriptions). Inkelas \& Cho predict that the two 
cases are typologically distinct: that coda lenition processes are systematically blocked in geminates, whereas other processes vary in this regard. But no such distinction emerges from the cases considered in section 1. Rather, the data support the stronger generalization that spirantization and voicing processes never apply to geminates, regardless of the conditioning environment. Furthermore, Inkelas \& Cho's analysis rests upon the problematic assumption that lenition can be equated with sonority promotion, cf. section 2.1 .

In a footnote to their conclusion, however, Inkelas \& Cho (1993: 569) observe:

Although they are arbitrary under our analysis, certain of the allophonic alternations involving geminates have a plausible phonetic basis. For example, the fact that voicing is harder to maintain over longer durations might motivate the distribution of [voice] in Berber ... in which singletons but not geminates are voiced.

This, of course, is precisely the sort of analysis provided by the effort-based approach, described in sections 2 and 3.

\subsection{COMPARISON WITH A NON-EFFORT-BASED LENITION APPROACH. Since I am} presenting this account of the geminate lenition generalizations as a significant part of the motivation for an effort-based approach to lenition, an important question is whether these generalizations could be as elegantly captured without explicit reference to effort in the formalism. Let us consider a theory in which lenition is attributed to a scalar REDUCE constraint, favoring reduction of constriction degree (e.g. approximant < fricative < stop), homologous to LAZY, but without explicitly referring to effort. The blocking of lenition in geminates could attributed to markedness constraints such as *[+cont,-cons,+length], *[+voi,-son,+length], *NASAL + FRICATIVE CLUSTERS, etc. It might be argued that the stipulativeness of this collection of formally unrelated constraints is not a serious defect of the approach: these constraints may be grounded in effort considerations such as I have identified, but (so the argument goes) it is extraneous to the goal of phonological theory to express these considerations directly in the formalism.

However, it would be a mistake to suppose that the cross-linguistic geminate lenition generalizations are captured in such a theory. For under rankings in which REDUCE dominates one 
of the markedness constraints, the generalization embodied by the markedness constraint evaporates:

$>$\begin{tabular}{|l||c|c|}
\hline & REDUCE & $*[+$ cont,-cons,+length] \\
\hline \hline $\mathrm{pp}$ & $* * !$ & \\
\hline$\phi \phi$ & $*$ & $*$ \\
\hline
\end{tabular}

The markedness constraints must therefore be stipulated to be inviolable; however, this ranking condition holds true only under lenition: for the faithfulness constraints, e.g. IDENT(cont) and IDENT(voi), must be able to dominate the markedness constraints, otherwise contrastively voiced or continuant geminates are incorrectly ruled out. By comparison, under the effort-based approach, the geminate lenition generalizations follow from the constraint set, without any ranking stipulations (apart from intrinsic Paninian ranking). It therefore appears that direct reference to effort in the formalism does afford a substantially more elegant and insightful treatment of the geminate lenition generalizations. More generally, it is unclear how a non-effort-based approach, such as this REDUCE + markedness constraint system, could be extended to capture such aspects of lenition typology as the naturalness of lenition in intervocalic position, the increasing prevalence of lenition in faster speech rates, and the relation between spatial reduction of consonant constriction (in spirantization), temporal reduction (in degemination and flapping), and laryngeal adjustments (in voicing). In contrast, all these phenomena receive natural treatments under the effort-based approach, as outlined in section 2 .

\section{CONCLUSION}

By reducing geminate inalterability to considerations of effort minimization, the effortbased approach to lenition achieves a greater depth of explanation, as well as better empirical coverage, than previous accounts of this class of phenomena.

\section{REFERENCES}


Al-Mozainy, H. (1981) Vowel alternations in a Bedouin Hijazi Arabic dialect: abstractness and stress. Doctoral Dissertation. University of Texas, Austin.

Anderson, S. (1969) West Scandinavian Vowel Systems and the Ordering of Phonological Rules, Doctoral Dissertation, MIT.

Armstrong, L. (1964) The Phonetic Structure of Somali, Gregg Press, London.

Bauer, L. (1988) "What is Lenition?" Journal of Linguistics 24:2, 381-92.

Banner-Inouye, S. (1995), Trills, Taps and Stops in Contrast and Variation, Doctoral Dissertation, UCLA.

Beckman, J. (1997) Positional Faithfulness, Doctoral Dissertation, UMass-Amherst.

Beckman, M. et al. (1992) "The Interaction of Coarticulation and Prosody in Sound Change," Language and Speech 35, 45-58.

Benua, L. (1995) Identity Effects in Morphological Truncation, in Papers in Optimality Theory, J. Beckman, S. Urbanczyk \& L. Walsh (eds.), 77-136, UMass-Amerst GLSA.

Boersma, P. (1997a) Elements of Functional Phonology, ms., Instituut voor Fonetische Wetenschappen.

Boersma, P. (1997b) Sound Change in Functional Phonology, ms., Instituut voor Fonetische Wetenschappen.

Boersma, P. (1997c) Inventories in Functional Phonology, ms., Instituut voor Fonetische Wetenschappen.

Boersma, P. (1997d) How We Learn Variation, Optionality and Probability, ms., Instituut voor Fonetische Wetenschappen.

Borden, G. \& K. Harris (1980) Speech Science Primer: Physiology, Acoustics and Perception of Speech, Baltimore: Williams and Wilkins.

Browman, G. and L. Goldstein (1990) Tiers in Articulatory Phonology, with some Implications for Casual Speech, in J. Kingston and M.. Beckman (eds.) Papers in Laboratory Phonology I, Cambridge University Press. 
Burzio, L. (1997) Strength in Numbers, paper presented at Hopkins OT Workshop/University of Maryland Mayfest 1997, Baltimore.

Cho, Y. (1990) Parameters of Consonantal Assimilation, Doctoral Dissertation, Stanford University.

Chomsky, N. and M. Halle, Sound Pattern of English, New York: Harper \& Row.

Churma, D. On 'On Geminates,' ms., SUNY-Buffalo.

Clark, J. \& C. Yallop (1990) An Introduction to Phonetics and Phonology, Oxford: Basil Blackwell.

Clements, G. (1985) The Geometry of Phonological Features, Phonology Yearbook 2, 225-252.

Clements, G. (1986) Compensatory Lengthening and Consonant Gemination in Luganda, Phonology Year, in L. Wetzels and E. Sezer (eds.), Studies in Compensatory Lengthening, 37-77, Dordrecht: Foris.

Clements, G. (1990) The Role of the Sonority Cycle in Core Syllabification, in J. Kingston and M. Beckman (eds.) Papers in Laboratory Phonology I, Cambridge University Press.

Dayley, J. (1989) Tümpisa (Panamint) Shoshone Grammar, University of California Publications in Linguistics, vol. 115., UC Press.

Dell, F. and M. Elmedlaoui (1985) Syllabic Consonants and Syllabification in Imdlawn Tashlhiyt Berber, J. African Languages and Ling. 7, 105-130.

Dixon, R. (1977) A Grammar of Yidin, Cambridge: Cambridge University Press.

Donegan, P. and D. Stampe (1979) The Study of Natural Phonology, in D. Dinnsen (ed.) Current Approaches to Phonological Theory, 126-73, IU Press, Bloomington.

Elmedlaoui, M. (1993) Gemination and Spirantization in Hebrew, Berber, and Tigrinya: a FortisLenis Module Analysis, Linguistica Communicatio V, 1: 121-176.

Evans, N. (1996) Current Issues in the Phonology of Australian Languages, in J. Goldsmith (ed.), Handbook of Phonological Theory, 723-761, Oxford: Blackwell.

Flemming, E. (1995) Auditory Features in Phonology, Doctoral Dissertation, UCLA. 
Flemming, E. (1997) Phonetic Optimization, Compromise in Speech Production, paper presented at Hopkins OT Workshop/University of Maryland Mayfest 1997, Baltimore.

Foley, J. (1977) Foundations of Phonological Theory, Cambridge University Press.

Fortescue, M. (1984) West Greenlandic, Croom Helm, London.

Frisch, S. (1996) Similarity and Frequency in Phonology, Doctoral Dissertation, Northwestern University.

Furbee-Losee, L (1976) The Correct Language: Tojolabal, Garland, New York.

Gafos, A. (1997) On the Proper Characterization of 'Nonconcatenative' Languages, ms., Johns Hopkins University.

Giannelli, L. and L. Savoia (1979) Indebolimento consonantico in Toscana, Revista Italiana di Diallettologia 2: 23-58.

Goldsmith (1976) Autosegmental Phonology, Doctoral Dissertation, MIT.

Gordon, M. (in progress) A Phonetically-Driven Theory of Weight, Doctoral Dissertation, UCLA.

Grammont, M. (1933) Traité de Phonetique, Delgrave, Paris.

Greenberg, J. (1948) The Tonal System of Proto-Bantu, Word 4:3, 196-208.

Gudschinsky, S., H. Popovich \& F. Popovich (1970) Native Reaction and Phonetic Similarity in Maxakalí Phonology, Language 46:1, 77-88.

Guerssel, M. (1977) Constraints on Phonological Rules, Ling. Analysis 3:267-305.

Harris, James (1984) "La espirantización en castellano y su representación fonológica autosegmental," in Bartra et al. (eds.) Estudis Grammaticals, Universitat Autònoma de Barcelona, Bellaterra.

Harris, James (1969) Spanish Phonology, Cambridge Mass., MIT Press.

Harris, John (1990) Segmental Complexity and Phonological Government, Phonology 7: 255300.

Hayes, B. (1986) "Inalterability in CV Phonology," Language 62:2, 321-352.

Hayes, B. (1997) Phonetically-Driven Phonology: The Role of Optimality Theory and Inductive Grounding, ms., UCLA. 
Hayes, B. \& R. Kirchner (in progress) Articulatory Effort Modeling and Geminate Inalterability, ms., UCLA.

Hayes, B. \& T. Stivers (in progress) A Phonetic Account of Post-Nasal Voicing, ms., UCLA.

Hock, H. (1991) Principles of Historical Linguistics (2d ed.), Mouton de Gruyter, Berlin.

Hyman, L. (1985) A Theory of Phonological Weight, Dordrecht: Foris.

Inkelas, S. and Y. Cho (1991) Inalterability as Prespecification, Language 69:3, 529-574.

Itô, J. (1986) Syllable Theory in Prosodic Phonology, Doctoral Dissertation, UMass-Amherst.

Itô, J. \& A. Mester (1986) The Phonology of Voicing in Japanese: Theoretical Consequences of Morphological Accessibility, LI 17: 49-73.

Jacobs, H. (1994) Lenition in Optimality Theory, ms. ??

Jacobs, H. and L. Wetzels (1988) "Early French Lenition: a Formal Account of an Integrated Sound Change," in H. van der Hulst and N. Smith (eds.) Features, Segmental Structures and Harmony Processes, 105-129, Dordrecht, Foris.

Jun, J. (1995) Perceptual and Articulatory Factors in Place Assimilation: an Optimality Theoretic Approach, Doctoral Dissertation, UCLA.

Ka, O. (1994) Wolof Phonology and Morphology, Lanham, Maryland: University Press of America.

Kaun, A. (1994) The Typology of Rounding Harmony, Doctoral Dissertation, UCLA.

Kawasaki, H. (1982) An Acoustical Basis for Universal Constraints on Sound Sequences, Doctoral Dissertation, UC-Berkeley.

Keating, P. (1984) Phonetic and Phonological Representation of Stop Consonant Voicing, Language 60:2, 286-319.

Keating, P., W. Linker \& M. Huffman (1983) Patterns in Allophone Distribution for Voiced and Voiceless Stops, J. Phonetics 11, 277-290.

Kenstowicz, M. (1982) Gemination and Spirantization in Tigrinya. Studies in the Linguistic Sciences 12:1, 103-122. 
Kenstowicz, M. (1995) Base Identity and Uniform Exponence: Alternatives to Cyclicity, ms., MIT.

Kiparsky, P. (1973) How Abstract is Phonology, in O. Fujimura (ed.) Three Dimensions of Linguistic Theory, TEC Corp., Tokyo.

Kirchner, R. (1997) Contrastiveness and Faithfulness, Phonology 14:1, 83-111.

Kirchner, R. (in progress) Lenition in Phonetically Based Optimality Theory, Doctoral Dissertation, UCLA.

Kohler, K. (1991) The Phonetics/Phonology Issue in the Study of Articulatory Reduction, Phonetica 48, 180-192.

Ladefoged, P. and I. Maddieson (1996) The Sounds of the World's Languages, Blackwell, Oxford.

Lass, R. and J. Anderson (1975) Old English Phonology, Cambridge University Press, Cambridge.

Lavoie, L. (1996) Consonant Strength: Results of a Data Base Development Project, Working Papers of the Cornell Phonetics Laboratory 11, 269-316.

Lindblom, B. (1983) "Economy of Speech Gestures," in MacNeilage, P. (ed.), Speech Production, New York, Springer Verlag.

Lindblom, B. (1990a) "Explaining Phonetic Variation: a Sketch of the H\&H Theory, in W. Hardcastle and A. Marchal (eds.) Speech Production and Speech Modelling, 403-439.

Lombardi, L. (1991) Laryngeal Features and Laryngeal Neutralization, Doctoral Dissertation, UMass-Amherst.

MacEachern, M. (1996) Laryngeal Similarity Effects in Quechua and Aymara, WCCFL 15.

Maddieson, I. (1984) Patterns of Sound, Cambridge University Press.

Maghway, J. (1995) Annotated Iraqw Lexicon, Tokyo: Institute for Study of Languages and Cultures of Asia and Africa.

Malone, J. (1993) Tiberian Hebrew Phonology, Winona Lake, Indiana: Eisenbrauns. 
Mascaró, J. (1987) A Reduction and Spreading Theory of Voicing and Other Sound Effects, ms. Universitat Autònoma de Barcelona.

Mascaró, J. (1983) "Continuant Spreading in Basque, Catalan, and Spanish," in M. Aronoff and R. Oehrle (eds.), Language Sound Structure, Cambridge, MIT Press.

McCarthy, J. (1979) Formal Problems in Semitic Phonology and Morphology, Doctoral Dissertation, MIT.

McCarthy, J. and A. Prince (1993) Generalized Alignment, ms., UMass-Amherst, Rutgers Univ.

McCarthy, J. and A. Prince (1995) Faithfulness and Reduplicative Identity, ms., UMass-Amherst, Rutgers Univ.

Mohanan, K. (1986) The Theory of Lexical Phonology, D. Reidel, Dordrecht.

Mous, M. (1992) A Grammar of Iraqw, Doctoral Dissertation, Leiden University.

Munro, P. \& D. Gaye (1991) Ay Baati Wolof: a Wolof Dictionary, UCLA Occasional Papers in Linguistics.

Myers, J. (1996) Canadian Raising and the Representation of Gradient Timing Relations, paper presented at MCWOP.

Nelson, W. (1980) Performance Bounds in Speech Motor Control of Jaw Movements, Ms., Bell Laboratories.

Ní Chiosáin, M. (1991) Topics in the Phonology of Irish, Doctoral Dissertation, UMass. Amherst. Nordbustad, F. (1985) Iraqw Grammar, ms.-affiliation unknown.

Ohala, J. (1992) Alternatives To The Sonority Hierarchy For Explaining Segmental Constraints, Papers from the Parasession on the Syllable, CLS, 319-338.

Ohala, J. (1983) The Origin of Sound Patterns in Vocal Tract Constraints, in P. MacNeilage, ed., The Production of Speech, 189-216, Springer-Verlag, New York.

Ohala, J. (1981) The Listener as a Source of Sound Change, Papers from the Parasession on Language and Behavior, CLS, 178-203.

Padgett, J. (1991) Stricture in Feature Geometry, Doctoral Dissertation, UMass-Amherst. 
Pater, J. (1996) “*NC.” Proceedings of the North East Linguistic Society 26, Graduate Linguistic Student Association, University of Massachusetts, Amherst, 227-239.

Prince, A. and P. Smolensky (1993) Optimality Theory: Constraint Interaction in Generative Grammar, ms. Rutgers University, University of Colorado.

Rehg, K. \& D. Sohl (1981), Ponapean Reference Grammar, Honolulu: U. Hawaii Press.

Rischel, J. (1974) Topics in West Greenlandic Phonology, Akademisk Forlag, Copenhagen.

Rothenberg, M. (1969) The Breath-Stream Dynamics of Simple-Released-Plosive Production, Bibliotheca Phonetica 6, Basel: S. Karger.

Saib, J. (1977) A phonological study of Tamazight Berber: dialect of the Ayt Ndhir, Doctoral Dissertation, UCLA.

Sauvageot, S. (1965) Description synchronique d'un Dialecte wolof: le Parler du Dyolof (Mémoires de l'Institut Fondamental d'Afrique Noire 73), Dakar: IFAN.

Schein, B. and D. Steriade (1986) On Geminates, LI 17:4, 691-744.

Silverman, D. (1995) Phasing and Recoverability, Doctoral Dissertation, UCLA.

Smith, C. (1992) The Timing of Vowel and Consonant Gestures, Doctoral Dissertation, Yale University.

Steriade, D. (1993) Positional Neutralization, ms., UCLA.

Steriade, D. (1995) Underspecification and Markedness, in J. Goldsmith (ed.) The Handbook of Phonology, Oxford, Basil Blackwell.

Steriade, D. (1996) Paradigm Uniformity and the Phonetics-Phonology Boundary, paper presented at Lab. Phon.

Steriade, D. and B. Schein (1998) "On Geminates," LI 17:4, 691-744.

Street, J. (1962) Khalkha Structure, Uralic and Altaic Series 24, Indiana University Publications in Linguistics, Bloomington.

Stone, M. (1996) Laboratory Techniques for Investigating Speech Articulation, in W. Hardcastle and J. Laver (eds.), The Handbook of the Phonetic Sciences, 11-32, Oxford: Blackwell. 
Thráinsson, H. (1978) On the Phonology of Icelandic Pre-Aspiration, Nordic Journal of Linguistics 1, 3-54.

Trail, Ronald (1970) The Grammar of Lamani, SIL/University of Oklahoma.

Westbury, J. and P. Keating (1986) On the Naturalness of Stop Consonant Voicing, Journal of Ling., 22, 145-66.

Whitely, W. (1958) A Short Description of Item Categories in Iraqw, Kampala: East African Institute of Social Research.

Wright, R. (1996) Consonant Clusters and Cue Preservation in Tsou, Doctoral Dissertation, UCLA.

Zipf, G. (1949) Human Behavior and the Principle of Least Effort, Cambridge: Addison-Wesley. Zwicky, A. (1972) On Casual Speech. CLS 8. 